\title{
A Study on Internal Explosion Testing of the "Rigid-Flexible-Rigid" Three-Layer Sealed Structure
}

\author{
Y. L. Xue $(\mathbb{D}$, D. G. Tang $(\mathbb{D}$, Z. Z. Li $(\mathbb{D}$, L. Z. Shao, Z. Liao, W. X. Chen $(\mathbb{D}$, and R. L. Zhen
}

State Key Laboratory of Disaster Prevention \& Mitigation of Explosion \& Impact, College of Defense Engineering, Army Engineering University of PLA, Nanjing, Jiangsu 210007, China

Correspondence should be addressed to Y. L. Xue; karl_xue88@outlook.com and D. G. Tang; tdg6206@163.com

Received 18 August 2017; Revised 10 November 2017; Accepted 4 December 2017; Published 8 January 2018

Academic Editor: Marcello Vanali

Copyright (c) 2018 Y. L. Xue et al. This is an open access article distributed under the Creative Commons Attribution License, which permits unrestricted use, distribution, and reproduction in any medium, provided the original work is properly cited.

Multilayered combination of protective structures is an important means of effectively weakening the explosive shockwave. On this basis, a "rigid-flexible-rigid" three-layer sealed structure was proposed in this paper and two models for the sealed structure were designed. Meanwhile, internal explosion tests of the two models were conducted. One model used foam concrete as the energy absorbing material and the other used dense sand. The comparisons between the test results and the computed results obtained from the formulae were made, and the test results agreed well with the computed results. Test results showed that both models had favorable energy-dissipating capacity, and the model that used foam concrete as the energy absorbing material had a superior energy-dissipating capacity.

\section{Introduction}

The rapid development of high explosives has placed higher demands on the resistance, safety, and sealing performance of explosive containment vessel. There are two methods to enhance the antiknock performance of explosive containment vessel. One method is to increase the thickness of explosive containment vessel or use higher strength material. This method will make it difficult to manufacture and transport and also will increase the economic costs [1-3]. The other method is to use the multilayered structure or composite material to enhance antiknock performance of explosive containment vessel $[4,5]$. In recent years, the multilayered structure form of explosive containment vessel is more and more widely used. As was pointed in the previous studies, the multilayered structure consisted of layers of different materials that can effectively weaken explosive shockwave [6-9]. In this paper, a simultaneously rigid and flexible multilayered sealed structure (called "rigid-flexiblerigid" three-layer sealed structure) was proposed and two models for the sealed structure were designed, and internal explosion tests of the two models were conducted. Under the internal explosion, the "rigid-flexible-rigid" three layers sealed structure dissipated the explosive energy through the "flexible" layer's deformation and wave dissipation capacity and reduced the explosive energy acting on the outer "rigid" layer, to protect it from damage while improving the resistance and leak-proof capabilities of the structure.

\section{Overview of Test}

2.1. Test Models. In order to analyze the dynamic response of the "rigid-flexible-rigid" three-layer sealed structure under internal explosion, two test models were prepared with identical geometric dimensions and three-layer structure form of reinforced concrete (rigid layer), energy absorbing interlayer (flexible layer), and reinforced concrete (rigid layer). Model 1 was filled with foam concrete [10-13] as the energy absorbing interlayer and Model 2 was filled with dense sand [14-16]; these are two kinds of energy absorbing materials which are widely used in protective engineering.

The test models consisted of a cylindrical body and round reinforced concrete plates on both ends. The internal radius was $0.5 \mathrm{~m}$, the external radius was $1 \mathrm{~m}$, and the internal net length was $5 \mathrm{~m}$. The main body consisted of three layers, both the inner layer and outer layer were $0.175 \mathrm{~m}$ thick reinforced 


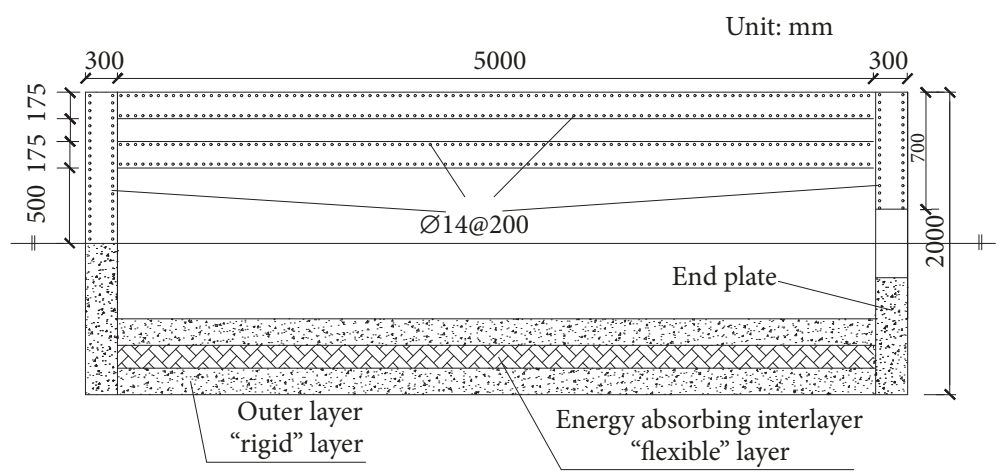

FIGURE 1: Dimensions diagram of the test model.

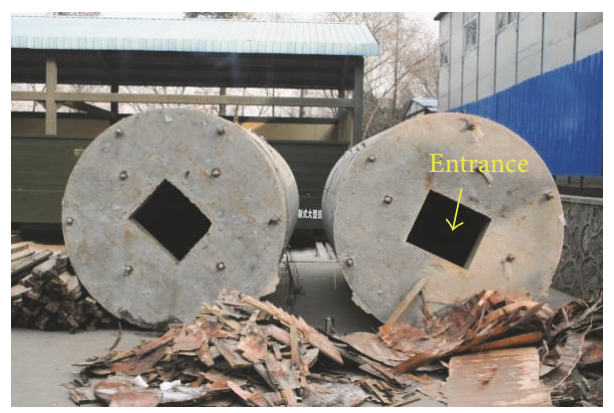

Figure 2: Test models.

TABLe 1: Parameters of foam concrete.

\begin{tabular}{lccc}
\hline$\rho_{f}\left(\mathrm{~kg} / \mathrm{m}^{3}\right)$ & $E_{f}\left(\mathrm{MP}_{\mathrm{a}}\right)$ & $\gamma$ & $\sigma_{y}\left(\mathrm{MP}_{\mathrm{a}}\right)$ \\
\hline 610 & 270 & 0.10 & 1.0 \\
\hline
\end{tabular}

concrete (rigid layer), and the $0.15 \mathrm{~m}$ thick interlayer was filled with energy absorbing materials (flexible layer). The reinforced concrete plates (end plates) on both sides with a thickness of $0.3 \mathrm{~m}$ were connected with the main body through embedded bolts. To facilitate placing test equipment and explosive charge in the structure, a $0.4 \mathrm{~m} \times 0.6 \mathrm{~m}$ (width $\times$ height) entrance with a steel protective door was opened on one end. The models could be locked to simulate a confined space and reduce the disturbance to the external environment during the test, as shown in Figures 1 and 2.

C40 concrete was poured on the main body and end plates of the test models. The inner layer and the outer layer as well as end plates used two-layer reinforcement. Hoop and axial reinforcing bars used $\Phi 14 \mathrm{~mm}$ rebar with a gap of $200 \mathrm{~mm}$. The parameters of the foam concrete and dense sand are shown in Tables 1 and 2.

\subsection{Measurement Point}

2.2.1. Pressure Measurement Point. Each model was equipped with 10 pressure sensors. Figure 3 shows a strain pressure sensor used for measuring the contact pressure between two adjacent layers; Figure 4 shows a piezoelectric pressure sensor (CY-YD205) used for measuring the explosive shockwave

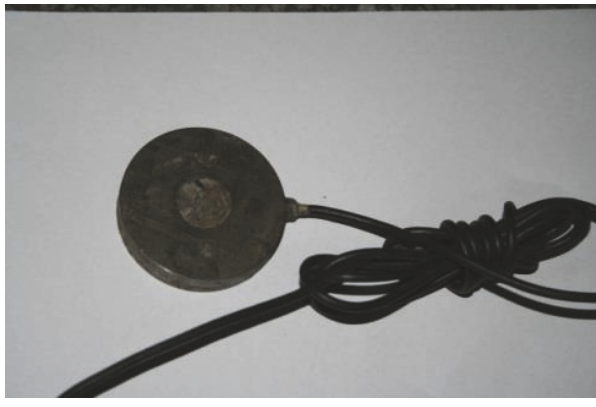

FIGURE 3: Strain pressure sensor.

TABle 2: Parameters of dense sand.

\begin{tabular}{lccc}
\hline$\rho_{d}\left(\mathrm{~kg} / \mathrm{m}^{3}\right)$ & $E_{s}\left(\mathrm{MP}_{\mathrm{a}}\right)$ & $\varphi\left(^{\circ}\right)$ & $C(\mathrm{kN})$ \\
\hline 1560 & 27.38 & 21.6 & 20 \\
\hline
\end{tabular}

load acting on the internal face. The position of pressure measuring points is shown in Figure 5; the serial number and description are shown in Table 3.

2.2.2. Strain Measurement Point. In order to investigate the deformation characteristics of the "rigid-flexible-rigid" three-layer sealed structure under internal explosion, each test model was equipped with 8 strain measurement points. As shown in Figure 6, the hoop strain measurement points were located on the circumferential reinforcement inside and outside of the inner layer of the center section A of each test 
TABLE 3: Description of pressure measurement points.

\begin{tabular}{|c|c|}
\hline Measurement points & The position of measurement points and introduction \\
\hline P-A-1 & $\begin{array}{l}\text { At internal surface of inner layer of section A } \\
\text { Measuring internal surface explosion shockwave load of inner layer of section A }\end{array}$ \\
\hline P-A-2 & $\begin{array}{l}\text { At external surface of inner layer of section A } \\
\text { Measuring the contact pressure between the energy absorbing materials and the inner layer of section A }\end{array}$ \\
\hline P-A-3 & $\begin{array}{l}\text { At internal surface of outer layer of section A } \\
\text { Measuring the contact pressure between the energy absorbing materials and the outer layer of section A }\end{array}$ \\
\hline P-B-1 & $\begin{array}{l}\text { At internal surface of inner layer of section B } \\
\text { Measuring internal surface explosion shockwave load of inner layer of section B }\end{array}$ \\
\hline P-B-2 & $\begin{array}{l}\text { At external surface of inner layer of section B } \\
\text { Measuring the contact pressure between the energy absorbing materials and the inner layer of section B }\end{array}$ \\
\hline P-B-3 & $\begin{array}{l}\text { At internal surface of outer layer of section B } \\
\text { Measuring the contact pressure between the energy absorbing materials and the outer layer of section B }\end{array}$ \\
\hline P-C-1 & $\begin{array}{l}\text { At internal surface of inner layer of section C } \\
\text { Measuring internal surface explosion shockwave load of inner layer of section C }\end{array}$ \\
\hline $\mathrm{P}-\mathrm{C}-2$ & $\begin{array}{l}\text { At external surface of inner layer of section } \mathrm{C} \\
\text { Measuring the contact pressure between the energy absorbing materials and the inner layer of section C }\end{array}$ \\
\hline P-C-3 & $\begin{array}{l}\text { At internal surface of outer layer of section } \mathrm{C} \\
\text { Measuring the contact pressure between the energy absorbing materials and the outer layer of section C }\end{array}$ \\
\hline P-D-1 & $\begin{array}{l}\text { At center of end plate of the structure } \\
\text { Measuring the explosion shockwave load of end plate }\end{array}$ \\
\hline
\end{tabular}

TABLE 4: Test conditions of the internal explosion.

\begin{tabular}{lccccc}
\hline Explosive sequences & 1 & 2 & 3 & 4 & 5 \\
Explosive charge quantity $/ W(\mathrm{~kg})$ & 0.15 & 0.2 & 0.3 & 0.475 & 0.8 \\
Scaled distance $/ \bar{R}\left(\mathrm{~m} / \mathrm{kg}^{1 / 3}\right)$ & 0.941 & 0.855 & 0.747 & 0.641 & 0.539 \\
\hline
\end{tabular}

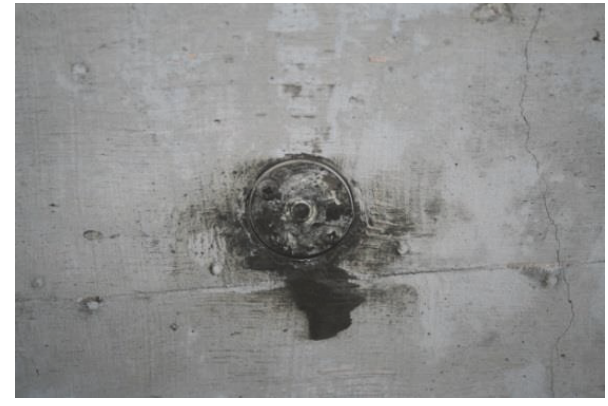

FIGURE 4: Piezoelectric pressure sensor.

model, as well as the outer layer; the position of the axial strain measurement points was the same as the hoop strain, but they were located on the axial reinforcement. The serial numbers of the hoop (axial) strain measurement points were A-H(J)-1, A-H(J)-2, A-H(J)-3, and A-H(J)-4 from inside to outside, $\mathrm{H}$ was the hoop strain measurement point, and J was the axial strain measurement point.

2.3. Test Conditions. Each model underwent 5 internal explosion tests; TNT was used as the charge and test conditions were shown in Table 4. A pothook was installed at the center peak of the test models, the explosive charge was hung on the pothook with a wire rope, and the wire rope length was precisely adjusted to ensure that the explosive center coincided with the test model's geometric center (as shown in Figure 7). The explosive charge was detonated with the electric detonator as shown in Figure 8.

\section{Analysis of Test Results}

In order to study the internal explosion effect of different explosive charge quantity and reveal the dynamic response of the three layers sealed structure, 10 pressure sensors and 8 strain gauges were used in each model. The explosive shockwave load, structural strain of the three layers sealed structure, and contact pressures between two adjacent layers were obtained.

3.1. Explosive Shockwave Load. The explosive shockwave load is often represented by the reflected shock overpressure and the reflected specific impulse. The reflected shock overpressure $P_{r}$ and the reflected specific impulse $I_{r}$ on the internal face of the "rigid-flexible-rigid" three-layer sealed structure obtained from the explosion tests were given in Tables 5 and 6 , and the position of 4 measurement points (P-A-1, P-B-1, P$\mathrm{C}-1$, and P-D-1) were shown in Table 3 and Figure 5.

The internal explosion was so complicated as a result of the interreflection of explosive shockwave on the internal face and the interaction of reflected waves, that current research on internal explosion of sealed structure tended to focus on 

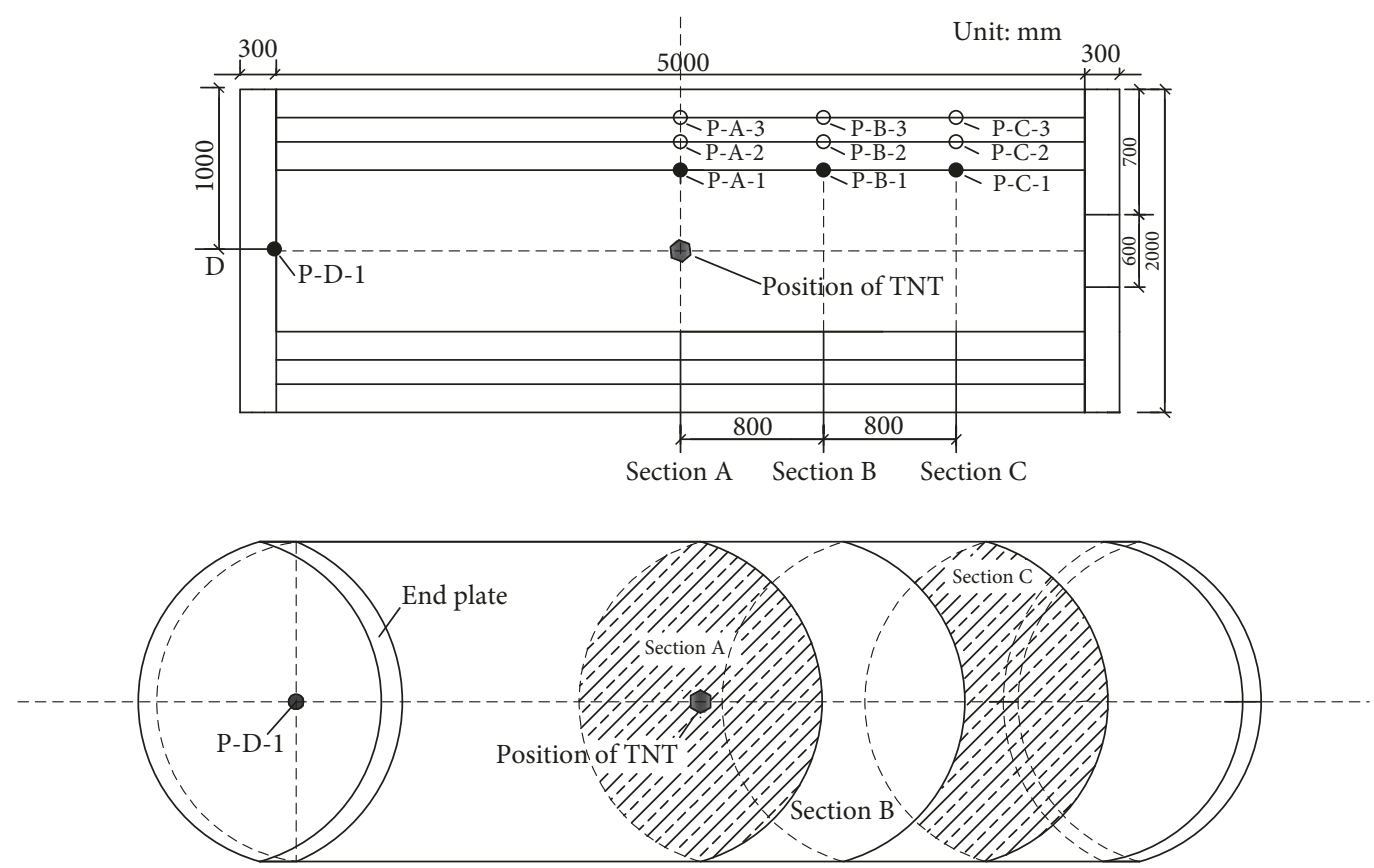

FIGURE 5: Position of pressure sensors.

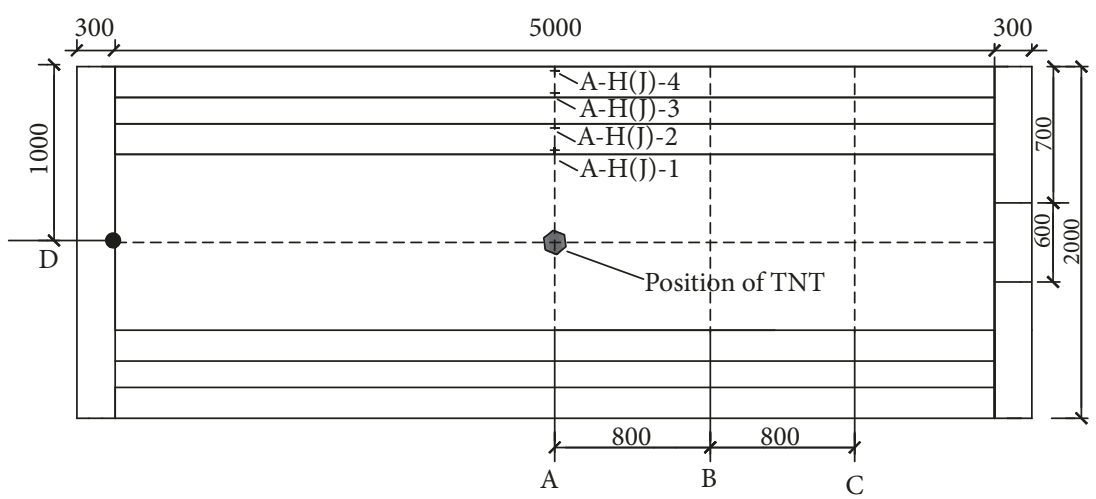

FIgURE 6: Position of strain measurement points.

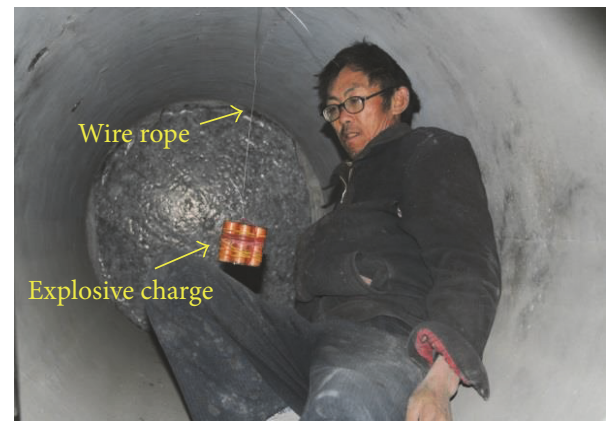

FiguRE 7: TNT charge.

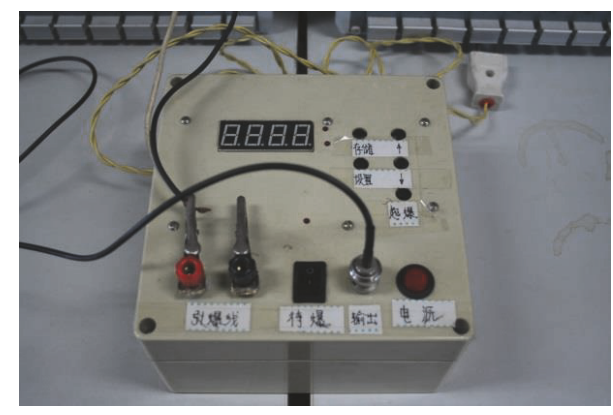

FIGURE 8: Electric detonator. the explosion center section such as section $\mathrm{A}$ in this paper. In our internal explosion tests, the reflected shock overpressure
$P_{r}$ and the reflected specific impulse $I_{r}$ on the internal face of section A (test results of P-A-1) were obtained.

To verify the creditability of test results, the comparisons between the test results of P-A-1 and the computed results 
TABLE 5: The reflected shock overpressure of the internal explosion $\left(\mathrm{MP}_{\mathrm{a}}\right)$.

\begin{tabular}{lcccccccc}
\hline \multirow{2}{*}{ Explosive charge/W $(\mathrm{kg})$} & \multicolumn{2}{c}{ P-A-1 } & \multicolumn{2}{c}{ P-B-1 } & \multicolumn{2}{c}{ P-C-1 } & \multicolumn{2}{c}{ P-D-1 } \\
& Model 1 & Model 2 & Model 1 & Model 2 & Model 1 & Model 2 & Model 1 & Model 2 \\
\hline 0.15 & 5.904 & 5.345 & 0.905 & 0.716 & 0.572 & 0.506 & 0.639 & 0.567 \\
0.2 & 7.071 & 7.086 & 1.022 & 0.911 & 0.735 & 0.523 & 1.042 & 0.742 \\
0.3 & 11.779 & 10.161 & 1.217 & 1.154 & 0.800 & 0.849 & 1.421 & 1.234 \\
0.475 & 16.221 & 17.136 & 1.923 & 1.727 & 1.274 & 0.915 & 1.639 & 1.886 \\
0.8 & 22.575 & 24.881 & 3.351 & 3.879 & 2.082 & 2.221 & 4.917 & 4.391 \\
\hline
\end{tabular}

TABLE 6: The reflected specific impulse of the internal explosion $\left(\mathrm{P}_{\mathrm{a}} \cdot \mathrm{s}\right)$.

\begin{tabular}{lcccccccc}
\hline \multirow{2}{*}{ Explosive charge/W $(\mathrm{kg})$} & \multicolumn{2}{c}{ P-A-1 } & \multicolumn{2}{c}{ P-B-1 } & \multicolumn{2}{c}{ P-C-1 } & \multicolumn{2}{c}{ P-D-1 } \\
& Model 1 & Model 2 & Model 1 & Model 2 & Model 1 & Model 2 & Model 1 & Model 2 \\
\hline 0.15 & 535.33 & 697.61 & 140.23 & 135.86 & 104.72 & 112.56 & 621.09 & 721.48 \\
0.2 & 831.11 & 708.42 & 209.55 & 182.33 & 182.31 & 146.59 & 780.56 & 778.52 \\
0.3 & 807.17 & 846.54 & 260.52 & 272.41 & 192.58 & 191.44 & 1395.47 & 1320.21 \\
0.475 & 1186.67 & 1224.80 & 401.76 & 377.18 & 286.71 & 249.37 & 1436.59 & 1629.42 \\
0.8 & 2054.95 & 1868.38 & 500.47 & 506.29 & 349.26 & 356.83 & 2254.51 & 2561.5 \\
\hline
\end{tabular}

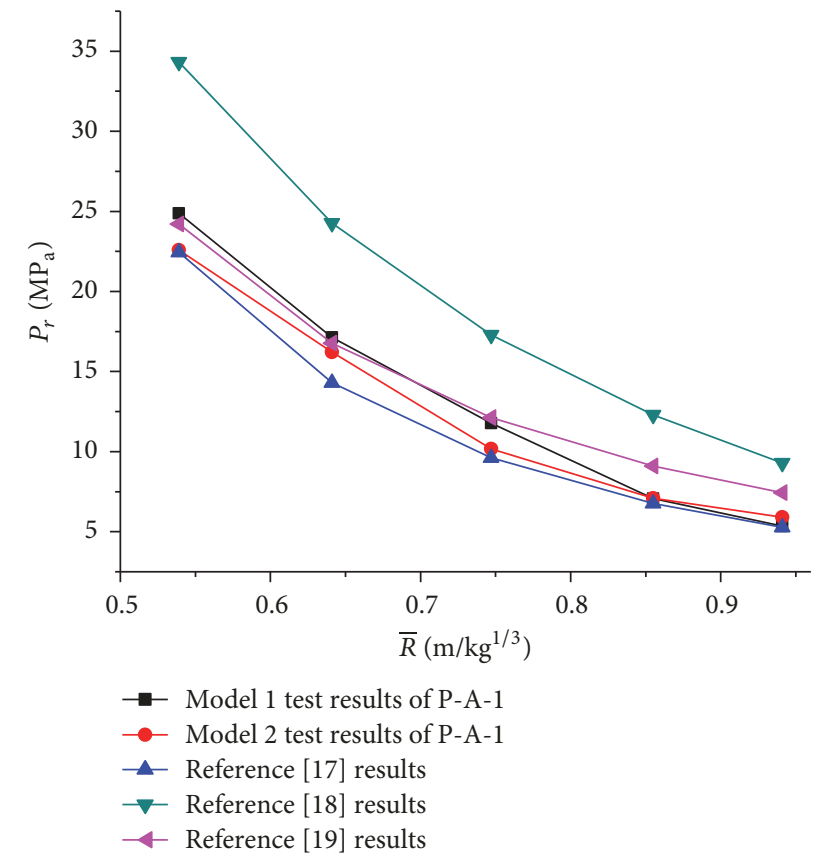

FIgURE 9: Comparison between the test data of reflected shock overpressure peak and computed results.

obtained from the formulae proposed by references [17-19] were made, and the comparative results of the reflected shock overpressure and the reflected specific impulse were shown in Figures 9 and 10.

Herein, we list the empirical and semianalytical formulae in the following.

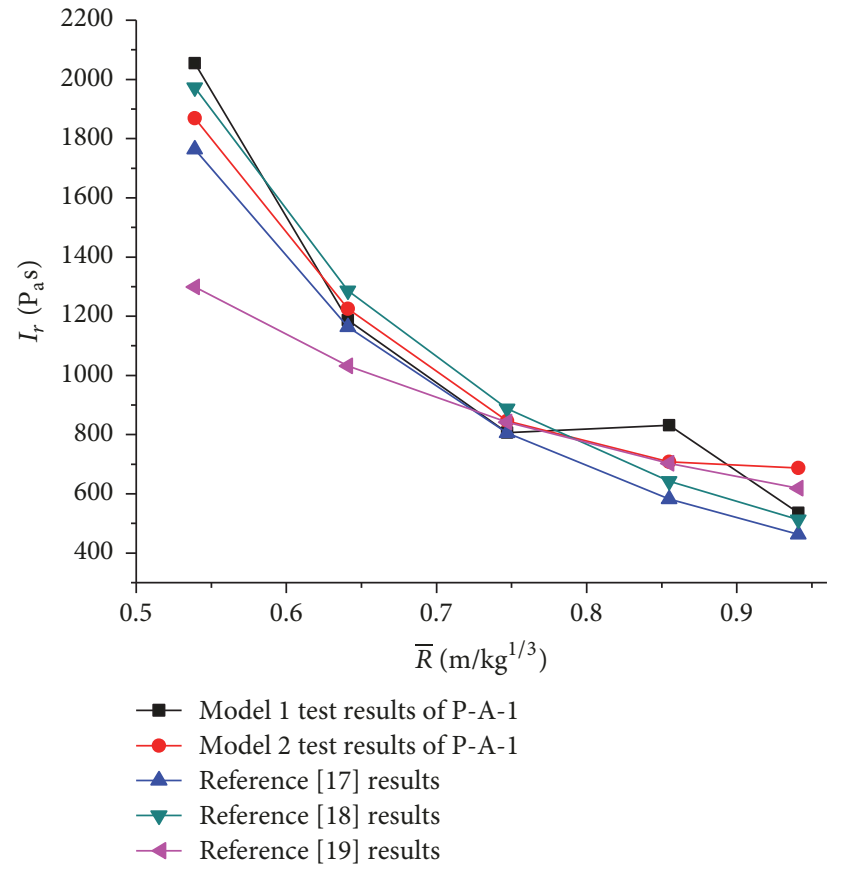

Figure 10: Comparison between the test data of reflected shock specific impulse and computed results.

\subsubsection{The Formulae Are Given by [17]}

$$
\begin{aligned}
& P_{r}=4.5 \bar{R}^{-2.6} \quad 0.2 \leq \bar{R} \leq 3\left(\mathrm{MP}_{\mathrm{a}}\right) \\
& I_{r}=800 \bar{R}^{-1.4} \cdot \sqrt[3]{W} \quad 0.2 \leq \bar{R} \leq 3\left(\mathrm{P}_{\mathrm{a}} \cdot \mathrm{s}\right) .
\end{aligned}
$$




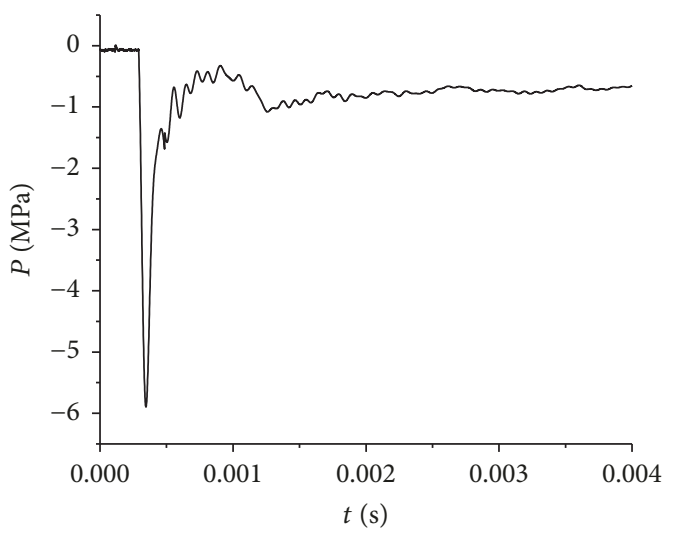

(a) $W=0.15 \mathrm{~kg}$

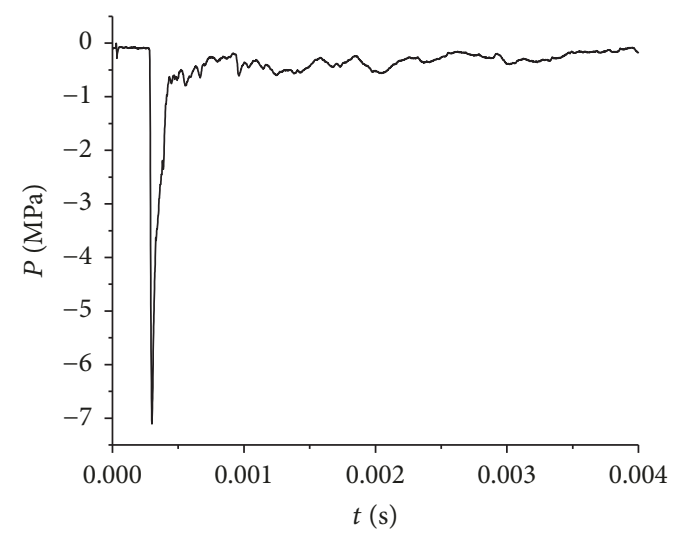

(b) $W=0.20 \mathrm{~kg}$

FIGURE 11: The time curve of the explosive shockwave of Model 1 at P-A-1.

\subsubsection{The Formulae Are Given by [18]}

$$
\begin{aligned}
& P_{r} \\
& = \begin{cases}-94.28+\frac{57}{\bar{R}}-\frac{0.104}{\bar{R}^{2}} & 0.05 \leq \bar{R}<0.3 \\
-14.43+\frac{17}{\bar{R}}+\frac{5}{\bar{R}^{2}} & 0.3 \leq \bar{R}<1 \\
0.038+\frac{8.3}{\bar{R}^{3}} & 1 \leq \bar{R}<3 \\
-0.0044+\frac{0.363}{\bar{R}}-\frac{0.852}{\bar{R}^{2}}+\frac{8.3}{\bar{R}^{3}} & 3 \leq \bar{R}<40\end{cases}
\end{aligned}
$$

$$
I_{r}= \begin{cases}\left(\frac{111}{\bar{R}}+\frac{382.3}{\bar{R}^{2}}\right) \cdot \sqrt[3]{W} & 0.05 \leq \bar{R}<0.3 \\ \left(\frac{588.3}{\bar{R}}+\frac{300.2}{\bar{R}^{2}}\right) \cdot \sqrt[3]{W} & 0.3 \leq \bar{R}<1 \\ \left(\frac{567.6}{\bar{R}}+\frac{321.8}{\bar{R}^{2}}\right) \cdot \sqrt[3]{W} & 1 \leq \bar{R}<40\end{cases}
$$

$\left(\mathrm{P}_{\mathrm{a}} \cdot \mathrm{s}\right)$

\subsubsection{The Formulae Are Given by [19]}

$$
\begin{aligned}
P_{r} & =6.53 \bar{R}^{-2.12} \quad 0.1<\bar{R}<1.0\left(\mathrm{MP}_{\mathrm{a}}\right) \\
I_{r} & = \begin{cases}248 \bar{R}^{-2.01} \cdot \sqrt[3]{W} & 0.06<\bar{R}<0.33 \\
571 \bar{R}^{-1.13} \cdot \sqrt[3]{W} & 0.33<\bar{R}<1.00\end{cases}
\end{aligned}
$$

$$
\left(\mathrm{P}_{\mathrm{a}} \cdot \mathrm{s}\right) .
$$

In formulae (1) (3), $P_{r}$ is the reflected shock overpressure, $I_{r}$ is the reflected specific impulse, $\bar{R}$ is the scaled distance, and $W$ is the explosive charge quantity.

Figures 9 and 10 showed that the test results of Model 1 and Model 2 were in good agreement with the formulae results, which demonstrated that our tests were reasonable and test results were credible.

As mentioned above, the reflected shock overpressure $P_{r}$ and the reflected specific impulse $I_{r}$ on the internal face of the "rigid-flexible-rigid" three-layer sealed structure obtained from the explosion tests were given in Tables 5 and 6. From Tables 5 and 6, the following is noticed. (1) The reflected shock overpressure and the reflected specific impulse at different measurement points increased with the increase of the explosive charge quantity and decreased with the increase of the distance far from the explosion center section. (2) It should be noted that the reflected shock overpressure and the reflected specific impulse of P-D-1 are even larger than P-B-1 and P-A-1. It is mainly because the reflected shockwave from the internal face was enhanced by colliding with each other at the center axis; then it generated an axial jet to collide with the end plate's inner face. It indicated that damage arising from internal explosion in cylindrical multilayered sealed structures may not be controlled by the deformation of the explosion center section; sometimes end plate will be damaged first. This is a noticeable problem for research and application on internal explosion of cylindrical multilayered sealed structures.

To deepen direct impression on the internal explosion shockwave, Figures 11 and 12 show the typical reflected shockwave curve of Model 1 at measurement points P-A-1 and P-D-1 with the explosive charge quantity of $0.15 \mathrm{~kg}$ and $0.2 \mathrm{~kg}$. The curve at P-A-1 reached the explosive shockwave peak soon after the shockwave arrived; then it decreased in an exponential form; the curve at P-D-1 reached the explosive shockwave peak soon after the shockwave arrived, but it showed several relative smaller reflected shockwave peaks during the descent stage. This was caused by superposition of the first impulse of the shockwave and the reflected waves of adjacent reflecting surfaces. It also confirmed the second conclusion observed from Tables 5 and 6.

3.2. Structural Strain. Tables 7 and 8 showed the strain peak of Model 1 and Model 2 at different measurement points, wherein "/" means test data was not detected. 


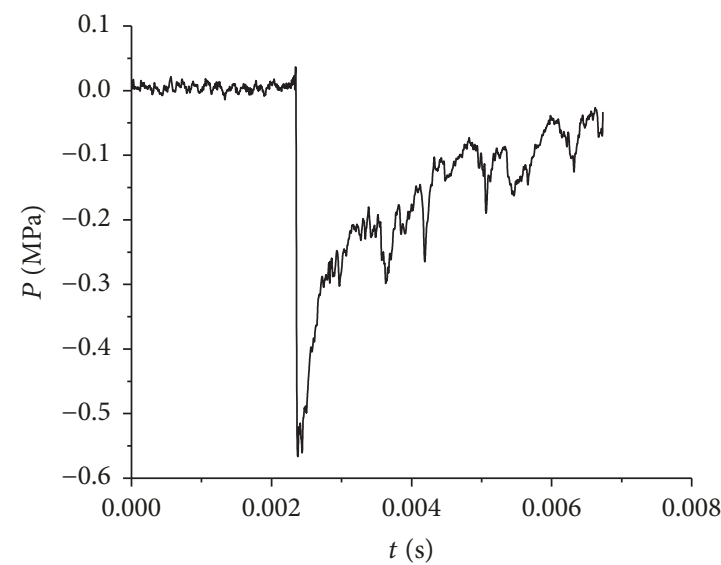

(a) $W=0.15 \mathrm{~kg}$

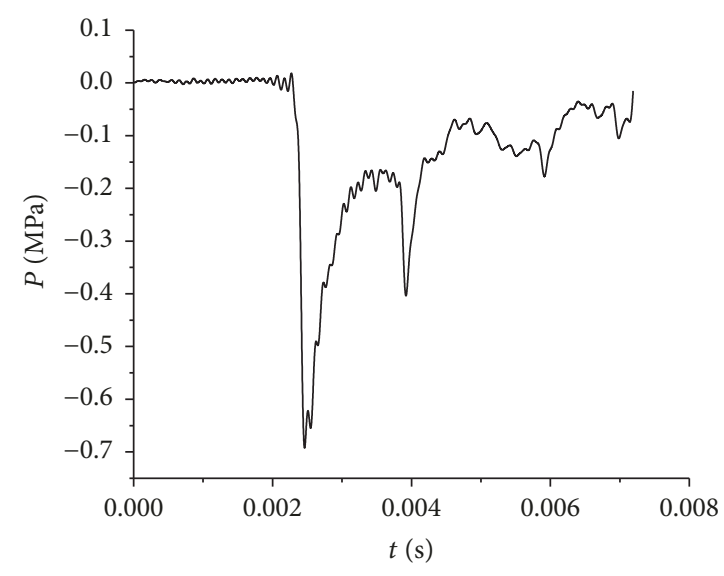

(b) $W=0.20 \mathrm{~kg}$

FIgURE 12: The time curve of the explosive shockwave of Model 1 at P-D-1.

TABLE 7: The strain peak of Model 1 at different measurement points $\left(\times 10^{-6}\right)$.

\begin{tabular}{|c|c|c|c|c|c|}
\hline \multirow{2}{*}{ Measurement points } & \multicolumn{5}{|c|}{ Explosive payloads/W (kg) } \\
\hline & 0.15 & 0.2 & 0.3 & 0.475 & 0.8 \\
\hline A-H-1 & 115.36 & 143.70 & 226.83 & 335.22 & 792.13 \\
\hline A-H-2 & 100.58 & 126.63 & 195.43 & 270.84 & 602.89 \\
\hline A-H-3 & 4.61 & 7.62 & 9.73 & 19.232 & 41.25 \\
\hline A-H-4 & 3.03 & 6.94 & 8.25 & 15.916 & 37.84 \\
\hline A-J-1 & 46.29 & 61.81 & 92.55 & 166.22 & 251.91 \\
\hline A-J-2 & 44.46 & 54.30 & 80.21 & 132.69 & 154.44 \\
\hline A-J-3 & 1 & 4.57 & 6.23 & 8.828 & 16.57 \\
\hline A-J-4 & l & 4.15 & 6.03 & 7.587 & 12.35 \\
\hline
\end{tabular}

TABLE 8: The strain peak of Model 2 at different measurement points $\left(\times 10^{-6}\right)$.

\begin{tabular}{|c|c|c|c|c|c|}
\hline \multirow{2}{*}{ Measurement points } & \multicolumn{5}{|c|}{ Explosive payloads/W (kg) } \\
\hline & 0.15 & 0.2 & 0.3 & 0.475 & 0.8 \\
\hline A-H-1 & 110.94 & 148.79 & 200.8 & 326.67 & 674.23 \\
\hline A-H-2 & 102.67 & 121.41 & 157.86 & 259.09 & 489.76 \\
\hline A-H-3 & 5.43 & 8.37 & 10.25 & 22.559 & 44.26 \\
\hline A-H-4 & 3.92 & 7.01 & 8.59 & 20.044 & 38.69 \\
\hline A-J-1 & 40.55 & 49.35 & 89.06 & 140.46 & 240.07 \\
\hline A-J-2 & 38.06 & 44.65 & 52.04 & 126.52 & 205.14 \\
\hline A-J-3 & 2.04 & 4.22 & 7.56 & 9.366 & 16.01 \\
\hline A-J-4 & I & 3.93 & 6.08 & 7.657 & 13.58 \\
\hline
\end{tabular}

In order to facilitate the analysis, the test data in Tables 7 and 8 had been sorted out and the results were shown in Figures 13-16. From Figures 13-16, we can demonstrate the following. (1) The strain peak increased with the increase of the explosive charge quantity. (2) Under the same explosive charge quantity, the hoop strain peak was greater than the axial strain peak at the same measurement point. (3) The strain peak (hoop strain and axial strain) of the outer layer was much smaller than the strain peak (hoop strain and axial strain) of the inner layer; the percentage ratio of them was about 10\% (Figures 13 and 14). It indicated that the energy absorbing interlayer ("flexible layer") has splendid energy-dissipating capacity. (4) At the same measurement point, the inner layer's strain peak (hoop strain and axial strain) of Model 1 were bigger than Model 2, while the outer layer's strain peak (hoop strain and axial strain) of Model 1 were smaller than Model 2, which predicted that the energydissipating capacity of Model 1 was better than Model 2 (Figures 15 and 16).

Figures 17 and 18 show Model 1's hoop strain wave and axial strain wave at different measurement points on section A with an explosive charge quantity of $0.8 \mathrm{~kg}$. 


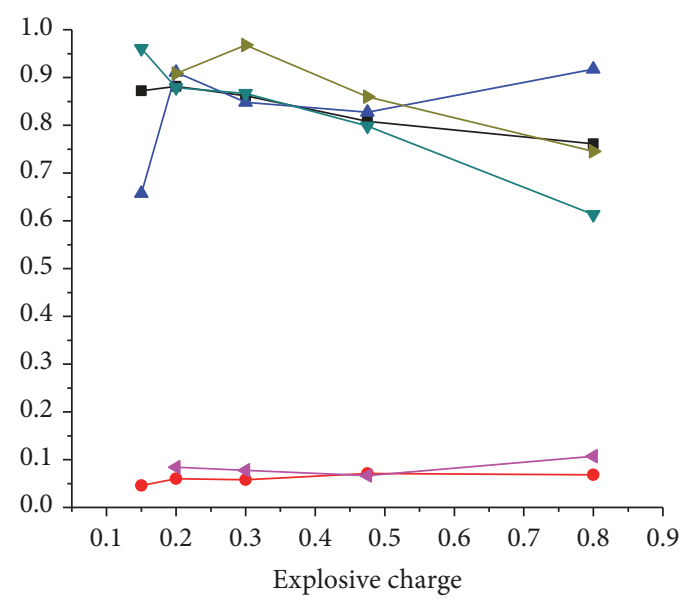

- The percentage ratio of A-H-2 to A-H-1
$\rightarrow$ The percentage ratio of A-H-3 to A-H-2
$\rightarrow$ The percentage ratio of A-H-4 to A-H-3
$\rightarrow$ The percentage ratio of A-J-2 to A-J-1
$\rightarrow$ The percentage ratio of A-J-3 to A-J-2
$\rightarrow$ The percentage ratio of A-J-4 to A-J-3

FIgURE 13: Percentage ratio of strain at each measurement point of Model 1.

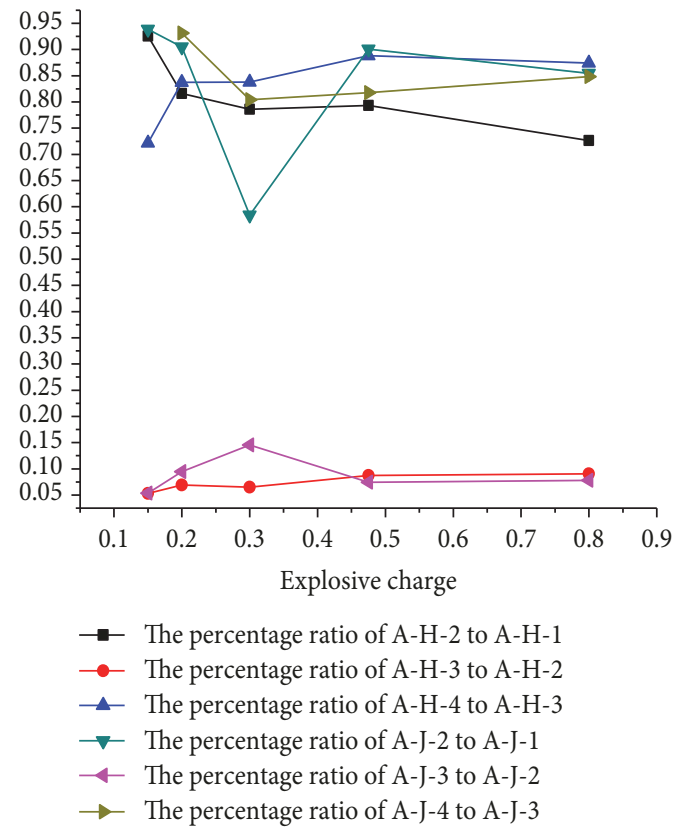

Figure 14: Percentage ratio of strain at each measurement point of Model 2.

3.3. Contact Pressure. The contact pressure between two adjacent layers of the "rigid-flexible-rigid" three layers sealed structure was an important indicator for the functioning of the energy absorbing layer. Table 9 showed the contact pressure peak at different measurement points under different explosive charge quantity.

In order to facilitate the analysis, the test data in Tables 5 and 9 had been sorted out and the results were shown in
Figures 19-26. From Figures 19-26, we can demonstrate the following. (1) The pressure peak increased with the increase of the explosive charge quantity. (2) The energy absorbing interlayer ("flexible layer") has good energy-dissipating capacity, the percentage ratio of P-A-2 to P-A-1 was about $1 \%$ $5 \%$ (Figure 20), and the most explosive energy was absorbed by the interlayer ("flexible layer"). (3) The energy-dissipating capacity of Model 1 was better than Model 2 (Figures 21-26). 

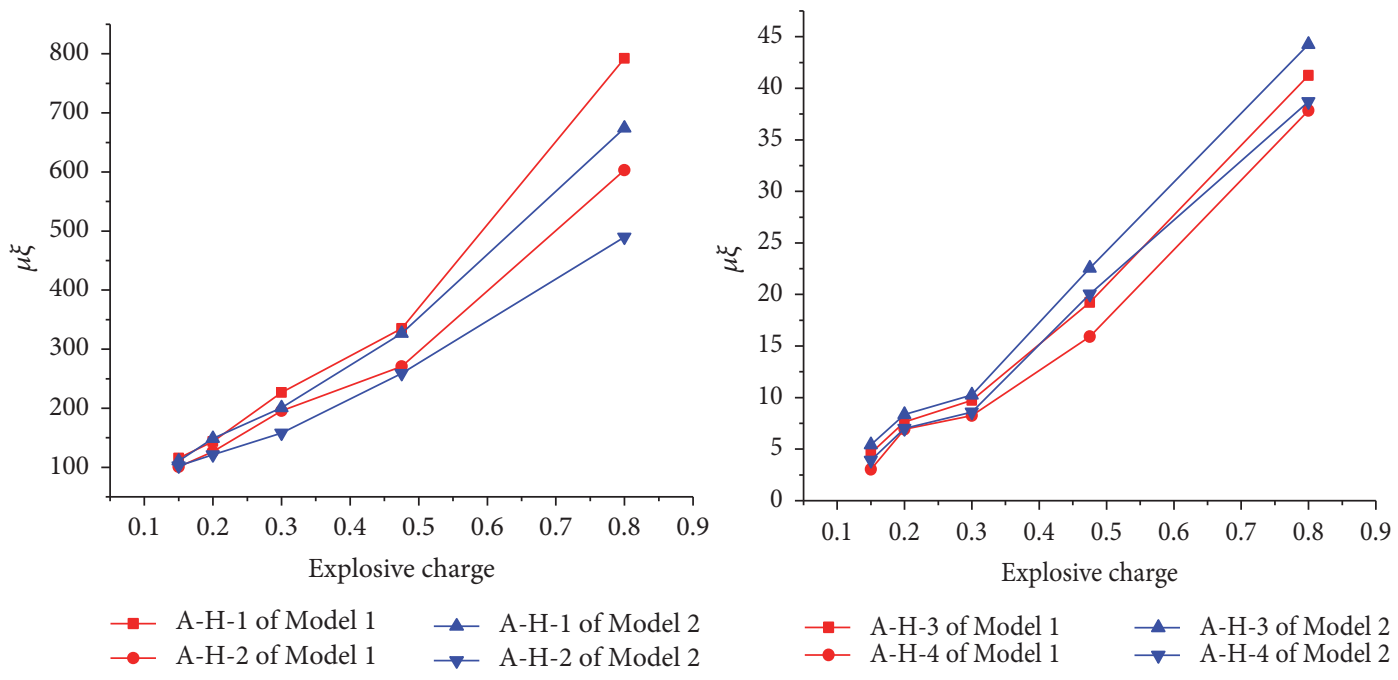

FIGURE 15: Hoop strain of two models.

TABLE 9: The contact pressure peak between two adjacent layers $\left(\mathrm{MP}_{\mathrm{a}}\right)$.

\begin{tabular}{|c|c|c|c|c|c|}
\hline \multirow{2}{*}{ Measurement points } & \multicolumn{5}{|c|}{ Explosive charge quantity/W (kg) } \\
\hline & 0.15 & 0.2 & 0.3 & 0.475 & 0.8 \\
\hline \multicolumn{6}{|l|}{ P-A-2 } \\
\hline Model 1 & 56.15 & 95.25 & 138.26 & 220.99 & 744.05 \\
\hline Model 2 & 68.42 & 188.26 & 281.42 & 433.88 & 1276.26 \\
\hline \multicolumn{6}{|l|}{ P-A-3 } \\
\hline Model 1 & 22.06 & 46.93 & 52.74 & 106.08 & 400.26 \\
\hline Model 2 & 46.52 & 67.46 & 91.78 & 164.27 & 522.49 \\
\hline \multicolumn{6}{|l|}{ P-B-2 } \\
\hline Model 1 & 22.04 & 31.28 & 36.95 & 49.22 & 185.45 \\
\hline Model 2 & 40.13 & 64.56 & 80.42 & 104.66 & 334.33 \\
\hline \multicolumn{6}{|l|}{ P-B-3 } \\
\hline Model 1 & 15.45 & 17.68 & 24.31 & 24.94 & 120.06 \\
\hline Model 2 & 16.98 & 26.44 & 36.01 & 52.88 & 162.70 \\
\hline \multicolumn{6}{|l|}{ P-C-2 } \\
\hline Model 1 & l & 12.81 & 15.56 & 17.02 & 67.57 \\
\hline Model 2 & 12.88 & 16.72 & 34.33 & 43.39 & 138.24 \\
\hline \multicolumn{6}{|l|}{ P-C-3 } \\
\hline Model 1 & I & I & 8.23 & 8.42 & 50.95 \\
\hline Model 2 & 12.45 & 15.14 & 20.08 & 25.02 & 121.49 \\
\hline
\end{tabular}

Figures 27 and 28 showed the time curve of the contact pressure of Model 1 and Model 2 when the explosive charge quantity was $0.8 \mathrm{~kg}$.

\section{Conclusions}

A "rigid-flexible-rigid" three-layer sealed structure containing the energy absorbing layer was proposed in this paper, and two models containing foam concrete as the energy absorbing layer (Model 1) and dense sand as the energy absorbing layer (Model 2) were designed. Internal explosion tests were conducted in these two models, and the test data such as the reflected shockwave pressure on the internal face, the structural strain, and the contact pressure between two adjacent layers of the "rigid-flexible-rigid" three-layer sealed structure were obtained. The main conclusions were as follows.

(1) The values of test data increased with the increase of the explosive charge quantity, which were in accord with the law of experience. The comparisons between the test results of P-A-1 and the computed results obtained from the formulae proposed by references [17-19] were made to verify the creditability of the test results; the test results of Model 1 and Model 2 were in good agreement with the formulae results, which demonstrated that our tests were reasonable and test results were credible. 

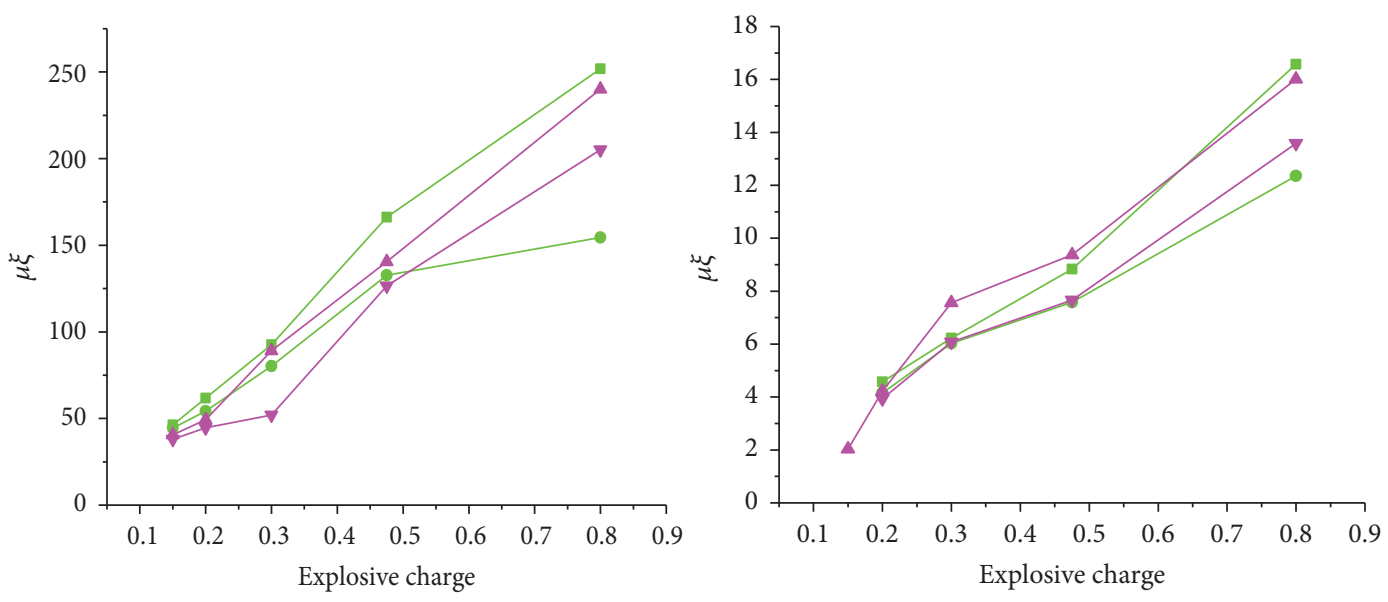

$\longrightarrow$ A-J-1 of Model $1 \longrightarrow$ A-J-1 of Model 2
$\longrightarrow$ A-J-2 of Model $1 \longrightarrow$ A-J-2 of Model 2

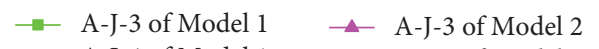

$\rightarrow$ A-J-4 of Model $1 \quad \checkmark \quad$ A-J-4 of Model 2

Figure 16: Axial strain of two models.

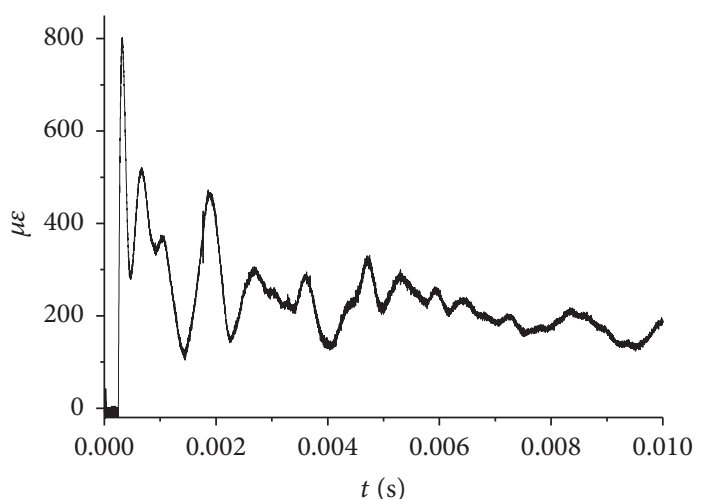

(a) A-H-1

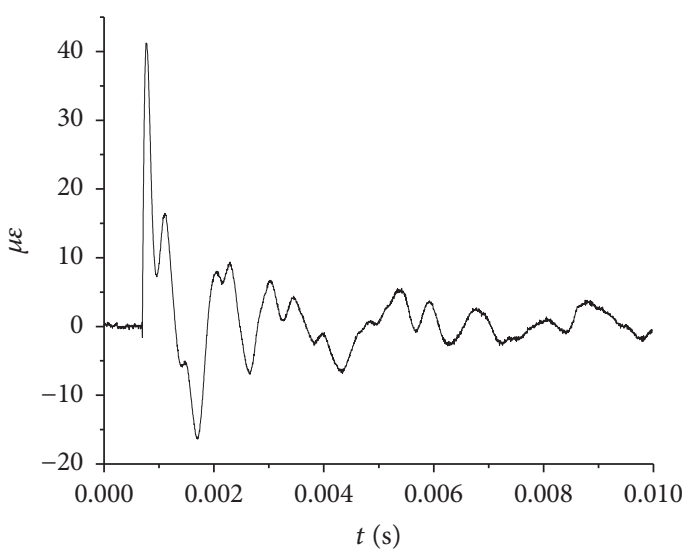

(c) A-H-3

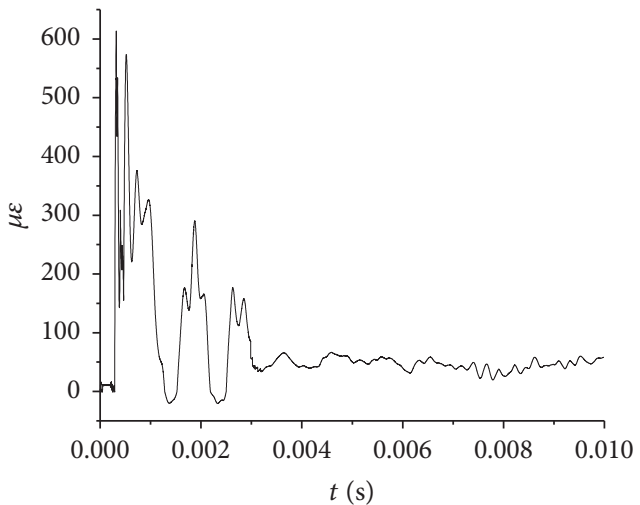

(b) A-H-2

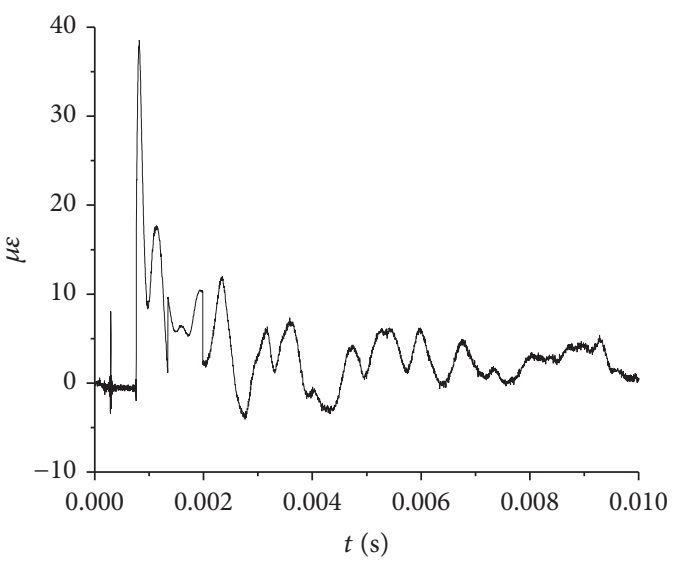

(d) A-H-4

FIGURE 17: Model 1's hoop strain wave with an explosive charge quantity of $0.8 \mathrm{~kg}$.

(2) The strain peaks (hoop strain and axial strain) of the outer layer were much smaller than the strain peaks (hoop strain and axial strain) of the inner layer; the percentage ratio of them was about 10\% (as shown in Figures 13 and 14).
The percentage ratio of $\mathrm{P}-\mathrm{A}-2$ (the contact pressure) to $\mathrm{P}-\mathrm{A}$ 1 (the reflected overpressure) was about 1\% 5\% (as shown in Figure 20). These indicated that the energy absorbing interlayers ("flexible layer") of both models have splendid 


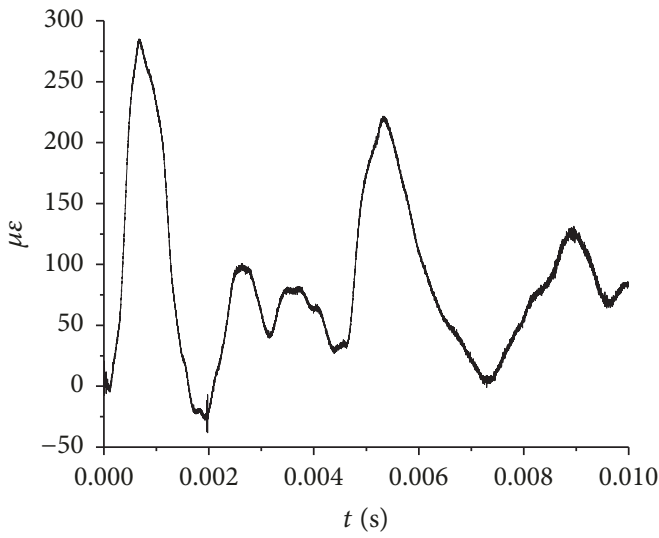

(a) A-J-1

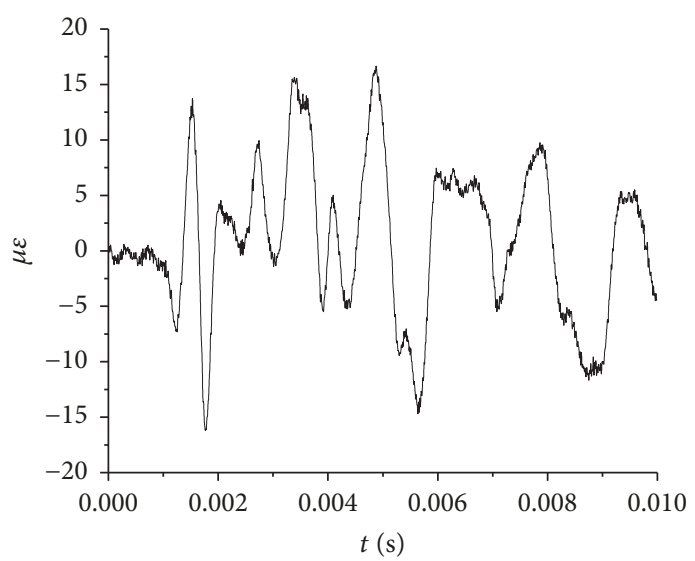

(c) A-J-3

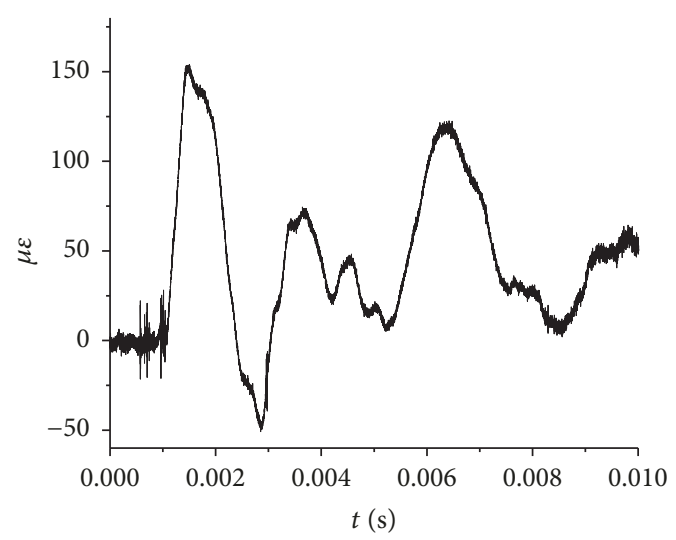

(b) $\mathrm{A}-\mathrm{J}-2$

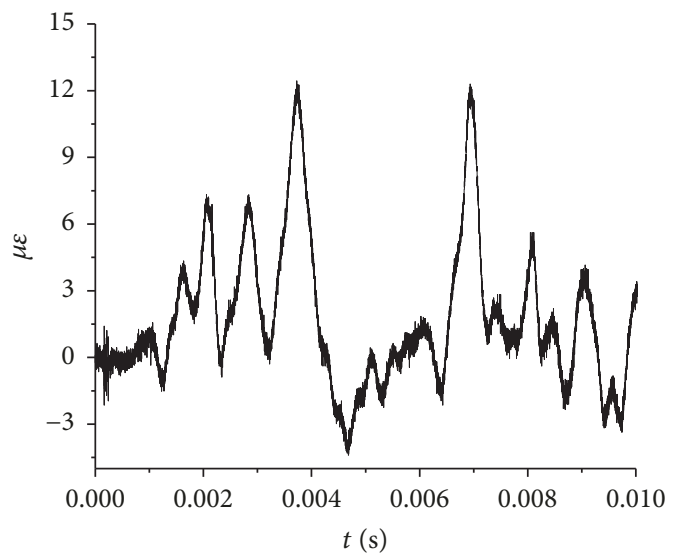

(d) A-J-4

FIGURE 18: Model 1's axial strain wave with an explosive charge of $0.8 \mathrm{~kg}$.

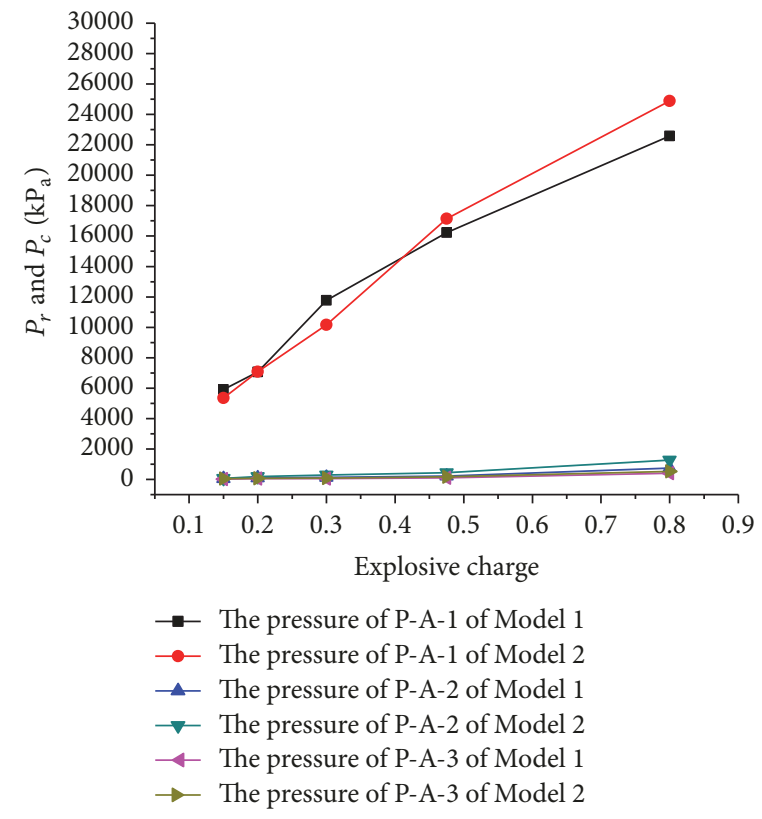

FIGURE 19: Pressure of each measurement point. 


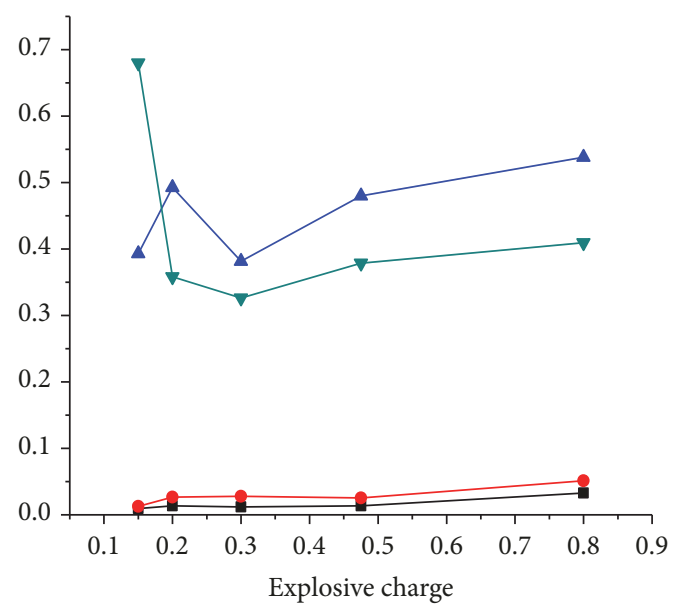

- The percentage ratio of P-A-2 to P-A-1 of Model 1

$\rightarrow$ The percentage ratio of P-A-2 to P-A- 1 of Model 2

$\_$The percentage ratio of P-A-3 to P-A-2 of Model 1

$\rightarrow$ The percentage ratio of P-A-3 to P-A- 2 of Model 2

FIgURE 20: Percentage ratio of pressure at each measurement point.

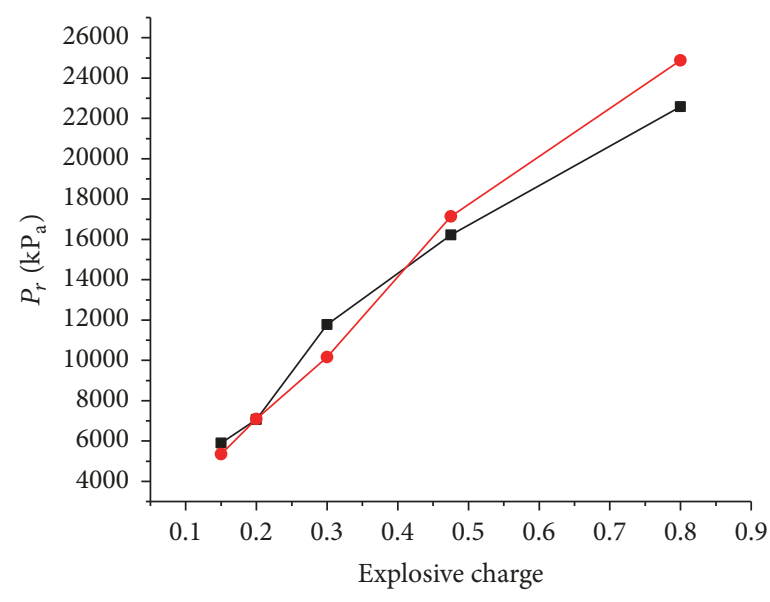

- The pressure of P-A-1 of Model 1

$\rightarrow$ The pressure of P-A-1 of Model 2

Figure 21: Pressure of P-A-1.

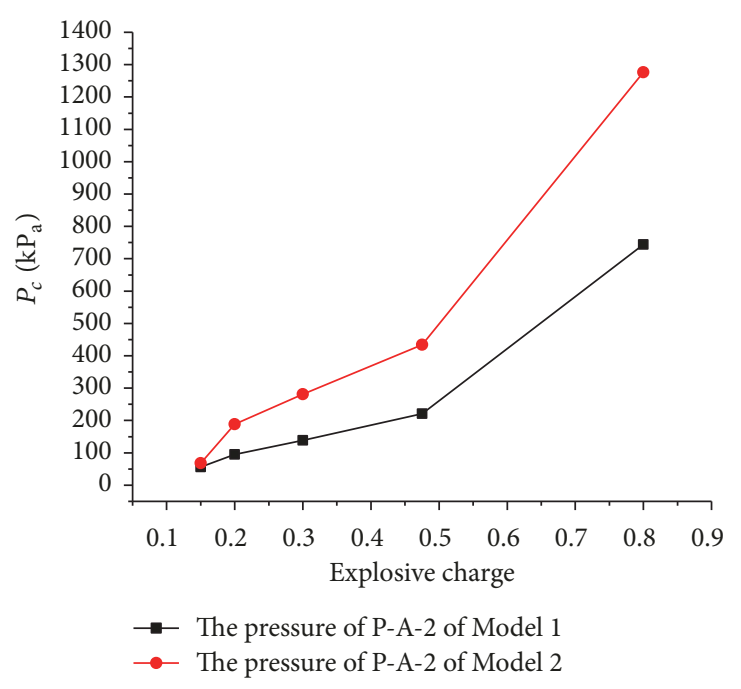

Figure 22: Pressure of P-A-2. 


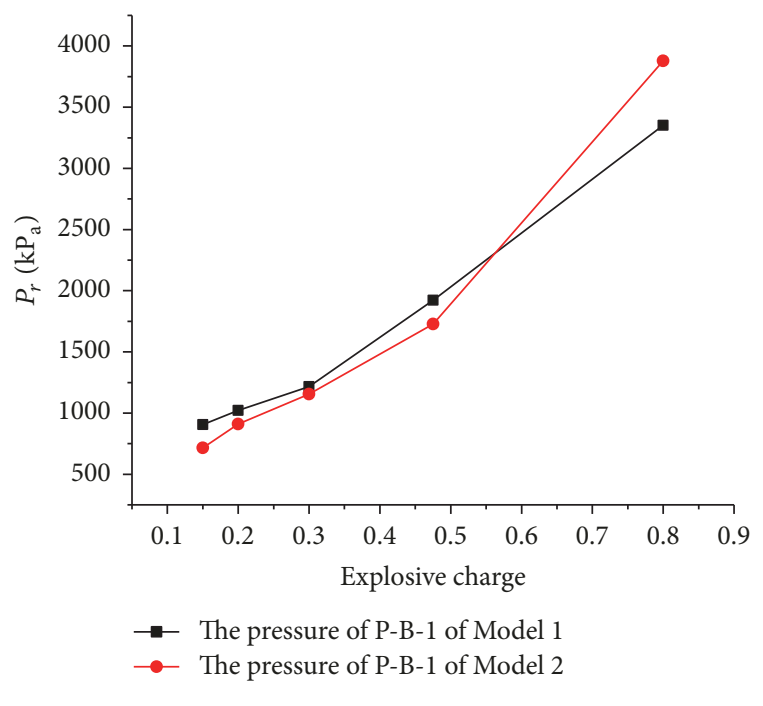

Figure 23: Pressure of P-B-1.

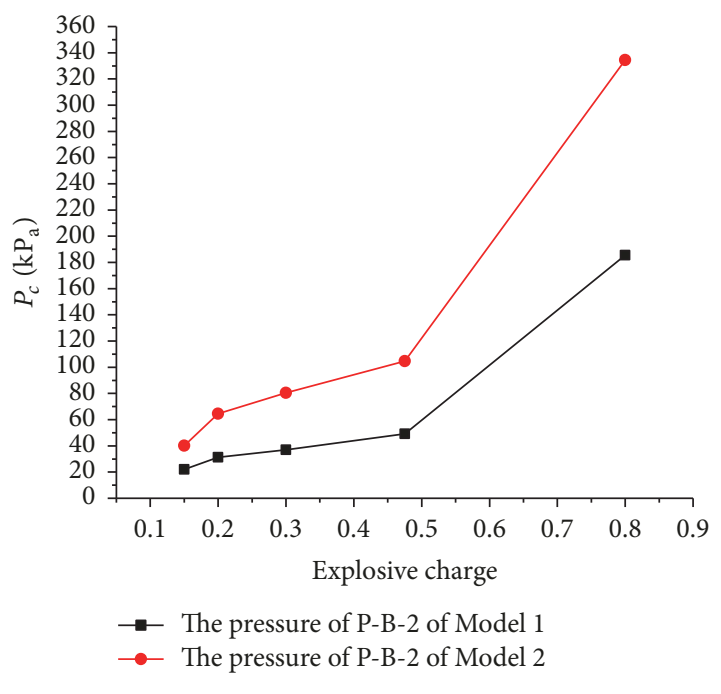

Figure 24: Pressure of P-B-2.

energy-dissipating capacity, and the most explosive energy was absorbed by the interlayers ("flexible layer").

(3) Under the same explosive charge quantity and at the same measurement point, the inner layer's strain peaks (hoop strain and axial strain) of Model 1 were bigger than Model 2, while the outer layer's strain peaks (hoop strain and axial strain) of Model 1 were smaller than Model 2, which predicted that the energy-dissipating capacity of Model 1 was better than Model 2 (as shown in Figures 15 and 16). The same opinion can be obtained by analyzing Figures 21-26. Figures 21, 23 and 25 showed that the pressures of Model 1 at measurement point $\mathrm{P}-\mathrm{A}-1 / \mathrm{P}-\mathrm{B}-1 / \mathrm{P}-\mathrm{C}-1$ were close to Model 2 at the same measurement point, while the pressures of Model 1 at measurement point P-A-2/P-B-2/P-C-2 were

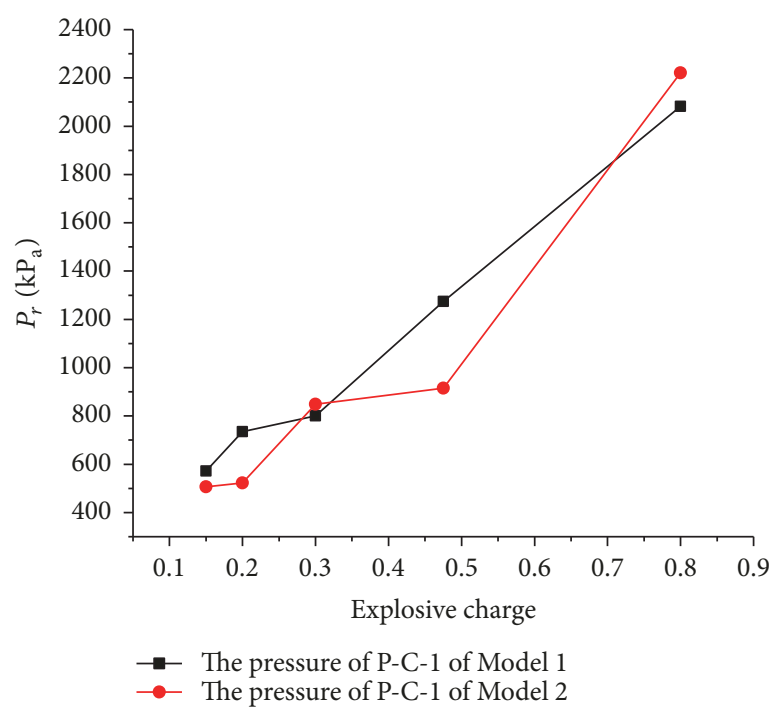

Figure 25: Pressure of P-C-1.

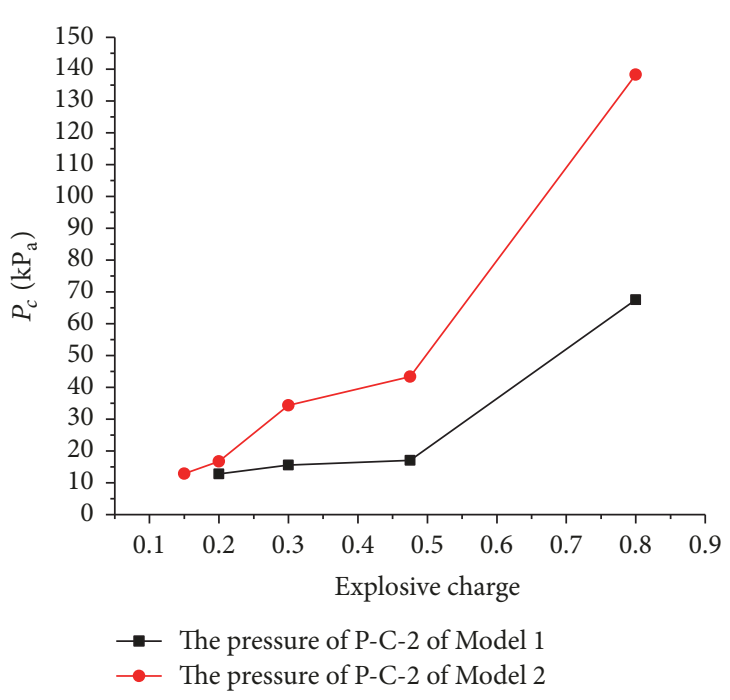

Figure 26: Pressure of P-C-2.

smaller than Model 2 at the same measurement point. Thus, the energy-dissipating capacity of Model 1 was better than Model 2.

\section{Symbols}

$\rho_{f}$ : Density of foam concrete

$E_{f}$ : Elastic modulus of foam concrete

$\gamma$ : Poisson's ratio of foam concrete

$\sigma_{y}$ : Yield stress of foam concrete

$\rho_{d}$ : Density of dense sand

$E_{s}$ : Elastic modulus of dense sand

$\varphi$ : Frictional angle of dense sand 


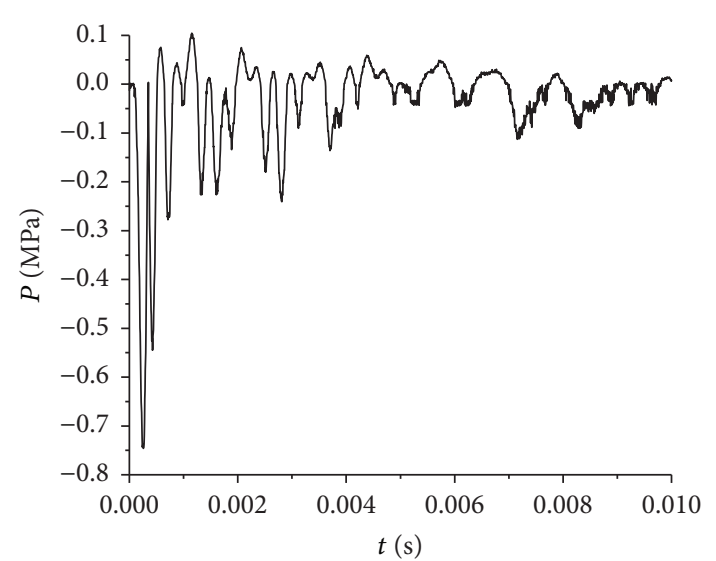

(a) P-A-2

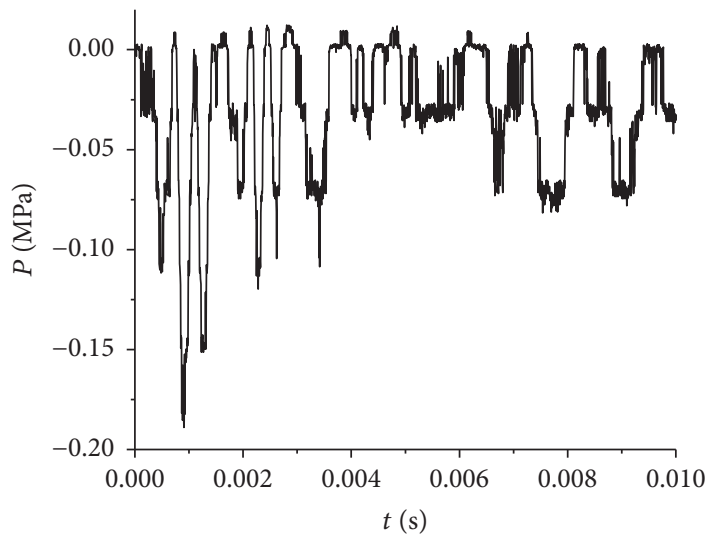

(c) P-B-2

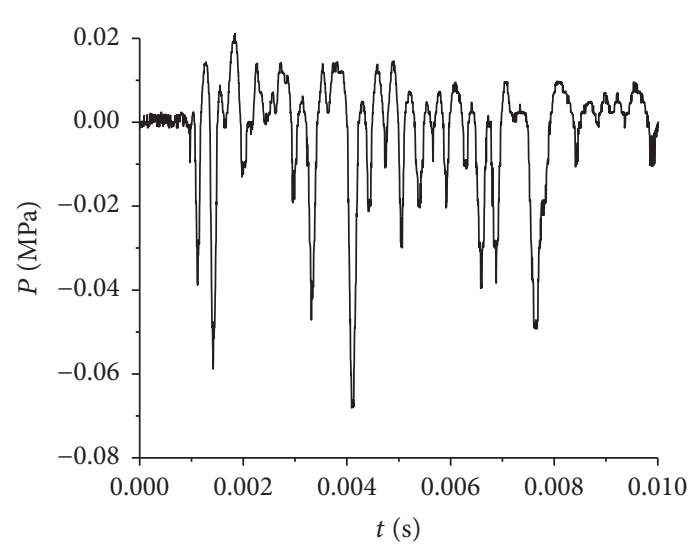

(e) $\mathrm{P}-\mathrm{C}-2$

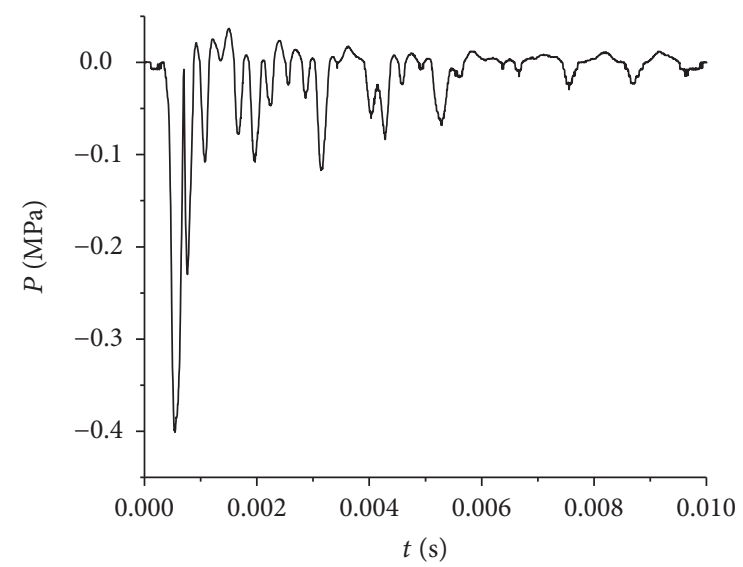

(b) P-A-3

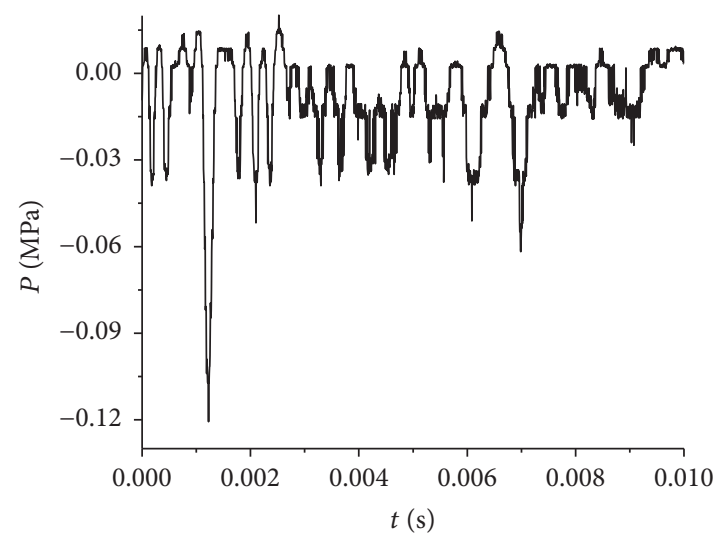

(d) P-B-3

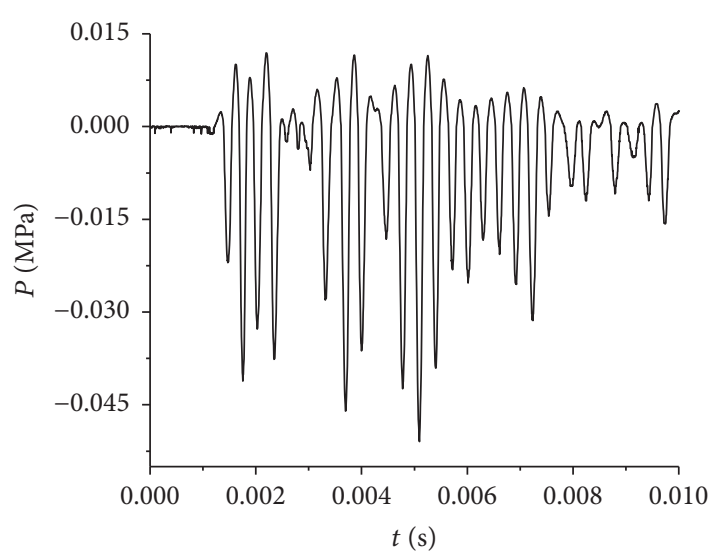

(f) P-C-3

FIGURE 27: The contact pressure wave of two adjacent layers of Model 1 with an explosive charge quantity of $0.8 \mathrm{~kg}$.

$C$ : Cohesion of dense sand

$W$ : Explosive charge quantity

$\bar{R}$ : Scaled distance.

\section{Conflicts of Interest}

The authors declare that there are no conflicts of interest regarding the publication of this paper. 


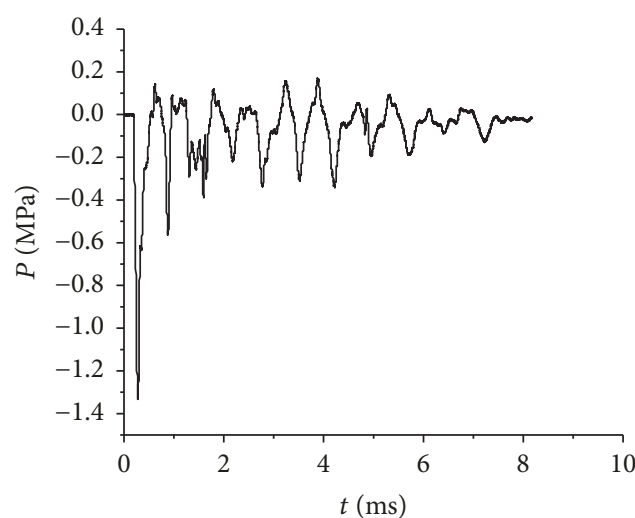

(a) P-A-2

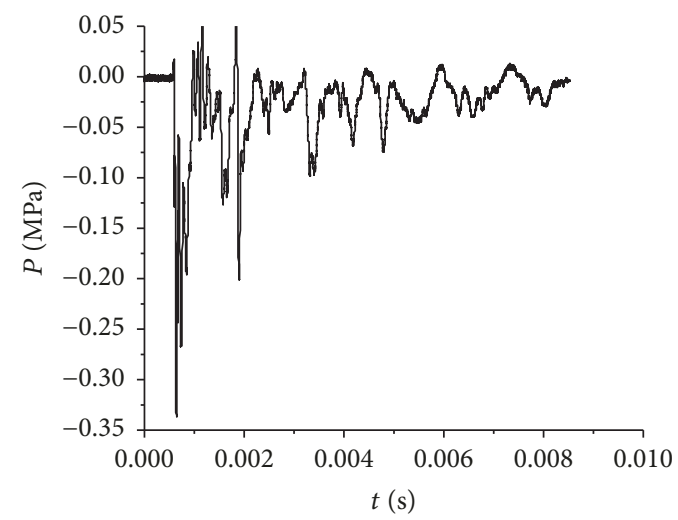

(c) P-B-2

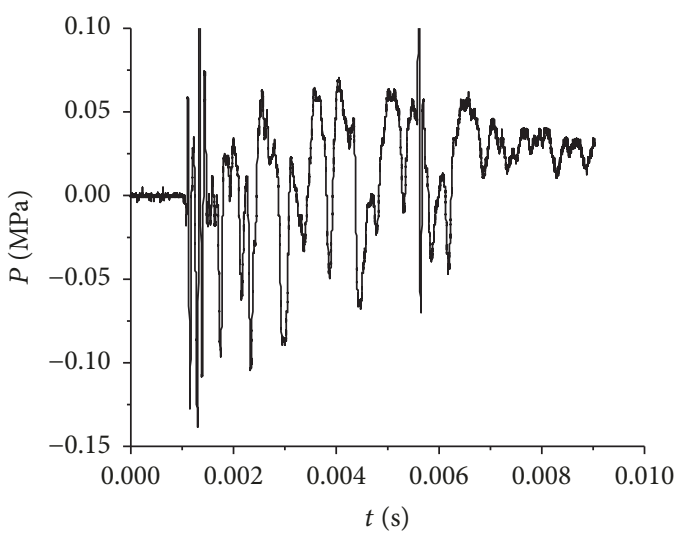

(e) $\mathrm{P}-\mathrm{C}-2$

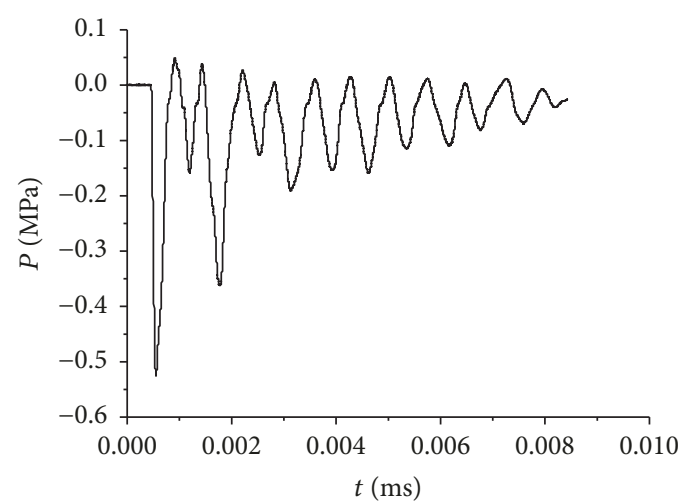

(b) P-A-3

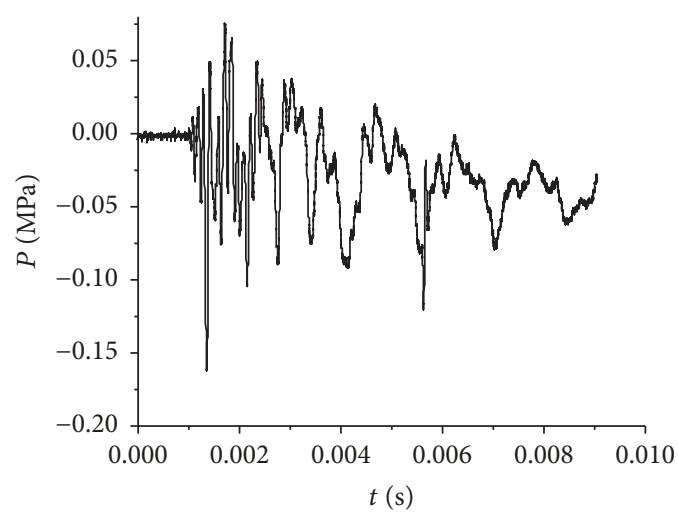

(d) P-B-3

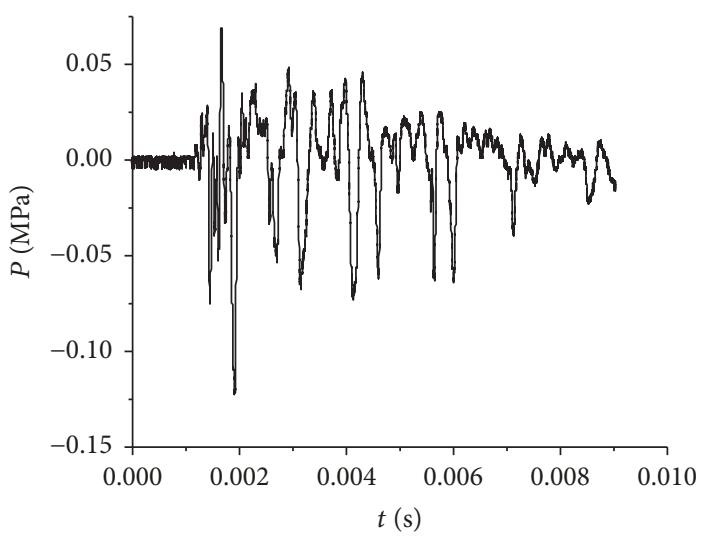

(f) P-C-3

FIGURE 28: The contact pressure wave of two adjacent layers of Model 2 with an explosive charge quantity of $0.8 \mathrm{~kg}$.

\section{Acknowledgments}

The authors would like to acknowledge the National Natural Science Foundation of China (Project nos. 51578541 and 51378498) for financial support.

\section{References}

[1] R. L. Martineau, C. A. Anderson, and F. W. Smith, "Expansion of cylindrical shells subjected to internal explosive detonations," Experimental Mechanics, vol. 40, no. 2, pp. 219-225, 2000.
[2] Y.-X. Cui, Y.-L. Hu, C.-M. Wang, H. Hu, and P.-W. Chen, "Dynamic response of multi-layer steel cylinder under internal intense blast loading," Explosion and Shock Waves, vol. 35, no. 6, pp. 820-824, 2015.

[3] W. J. Li, Q. L. Zeng, Y. L. Hu, H. Hu, and G. D. Liu, "Experimental study of antiknock performance of the steel cylinder reinforced by concrete," Concrete, vol. 251, no. 9, pp. 35-37, 2010.

[4] F.-P. Zhong, Y.-J. Ma, D.-Z. Zhang et al., "Research on plastic deformation of multi-layer cylindrical steel tube subjected to blasts of spherical and cylindrical charges," Binggong Xuebao/Acta Armamentarii, vol. 30, no. 2, pp. 194-196, 2009. 
[5] J.-Y. Zheng, G.-D. Deng, Y.-J. Chen et al., "Experimental investigation on dynamic response and fracture characteristics of discrete multilayered thick-walled explosion containment vessels," Baozha Yu Chongji/Explosion and Shock Waves, vol. 25, no. 6, pp. 506-511, 2005.

[6] H. Wan, Y. Li, and L. Zheng, "Vibration and damping analysis of a multilayered composite plate with a viscoelastic midlayer," Shock and Vibration, vol. 2016, Article ID 6354915, 10 pages, 2016.

[7] H. S. Türkmen, "Structural response of laminated composite shells subjected to blast loading: Comparison of experimental and theoretical methods," Journal of Sound and Vibration, vol. 249, no. 4, pp. 663-678, 2002.

[8] A. Maghsoodi, A. Ohadi, and M. Sadighi, "Calculation of wave dispersion curves in multilayered composite-metal plates," Shock and Vibration, vol. 2014, Article ID 410514, 6 pages, 2014.

[9] Z.-X. Wang and H.-S. Shen, "Nonlinear vibration and bending of sandwich plates with nanotube-reinforced composite face sheets," Composites Part B: Engineering, vol. 43, no. 2, pp. 411421, 2012.

[10] J. Wang, W. Guo, R. Zhao, Y. Shi, and L. Zeng, "Energyabsorbing properties and crushing flow stress equation of lightweight foamed concrete," Tumu Jianzhu yu Huanjing Gongcheng/Journal of Civil, Architectural and Environmental Engineering, vol. 35, no. 6, pp. 96-102, 2013.

[11] A. A. A. Samad, J. Hadipramana, A. M. A. Zaidi, and N. Mohamad, "Investigation on energy absorption of slab foamed concrete reinforced by polypropylene fibre subjected to impact loading," Advanced Materials Research, vol. 831, pp. 67-72, 2014.

[12] X. Tian, D. Zhang, and Y. Niu, "Mechanical and Energy Absorption Properties of Foamed Concrete under One-dimension Strain Compression," Modern Applied Science (MAS), vol. 10, no. 7, p. 195, 2016.

[13] M. Roderick Jones and L. Zheng, "Energy absorption of foamed concrete from low-velocity impacts," Magazine of Concrete Research, vol. 65, no. 4, pp. 209-219, 2013.

[14] X. Pei, Y. Liu, and D. Wang, "Study on the energy dissipation of sandy soil cushions on the rock-shed under rockfall impact load," Sichuan Daxue Xuebao (Gongcheng Kexue Ban)/Journal of Sichuan University (Engineering Science Edition), vol. 48, no. 1, pp. 15-22, 2016.

[15] L. Kong, Q. Su, Y. C. Wang, and R. Peng, "Mesoscopic mechanics and energy dissipation analysis of sand deformation under slow cyclic loading," Chinese Journal of Underground Space and Engineering, vol. 8, no. 2, pp. 268-300, 2012.

[16] D. W. Wang, D. Z. Zhang, Y. Li et al., "Experimental Study of Sand Wall Energy Absorption Effect on Blastwave," Journal of Experimental Mechnics, vol. 26, no. 1, pp. 37-42, 2011.

[17] H. F. Huo, Dynamic Characteristic Analysis and Experimental Study of Assembled Explosion Vessel. PhD Dissertation [Ph.D. thesis], Xi'an Jiao Tong University, 2000.

[18] Y. Lu and K. Xu, "Prediction of debris launch velocity of vented concrete structures under internal blast," International Journal of Impact Engineering, vol. 34, no. 11, pp. 1753-1767, 2007.

[19] D.-Z. Zhang, Y. Li, D.-W. Wang, C.-L. Wang, F.-P. Zhong, and J.-D. Lin, "Experiment investigations on normal reflected blast wave near the spherical explosive," Binggong Xuebao/Acta Armamentarii, vol. 30, no. 12, pp. 1663-1667, 2009. 


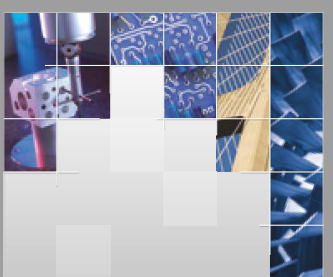

\section{Enfincering}
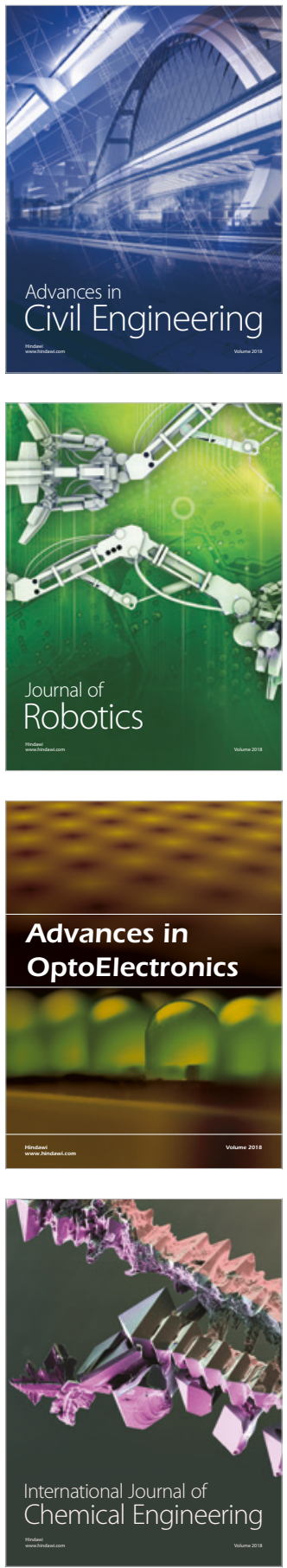

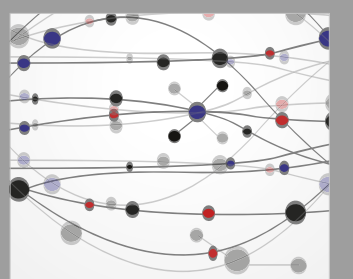

\section{Rotating \\ Machinery}

The Scientific World Journal

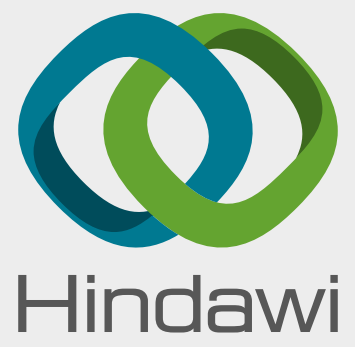

Submit your manuscripts at

www.hindawi.com
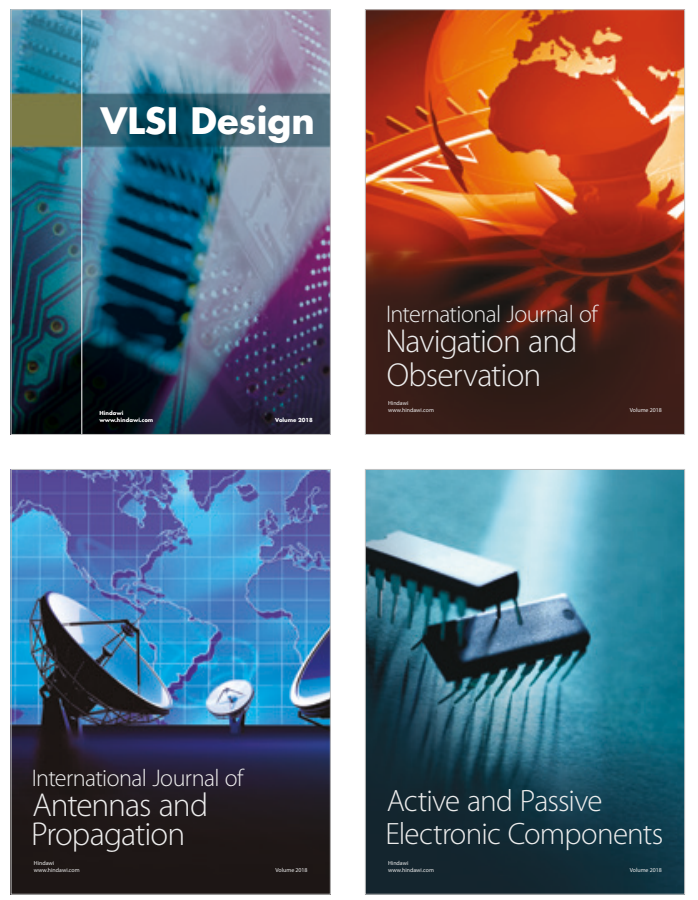
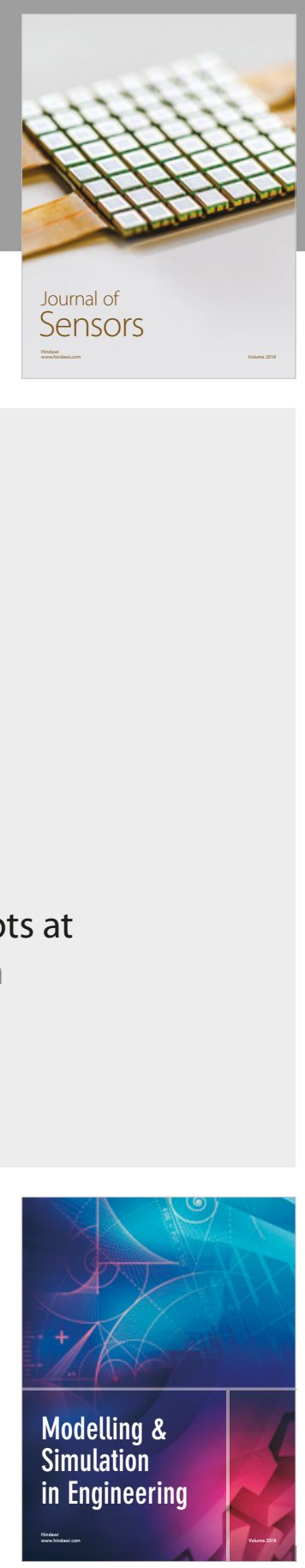

\section{Advances \\ Multimedia}
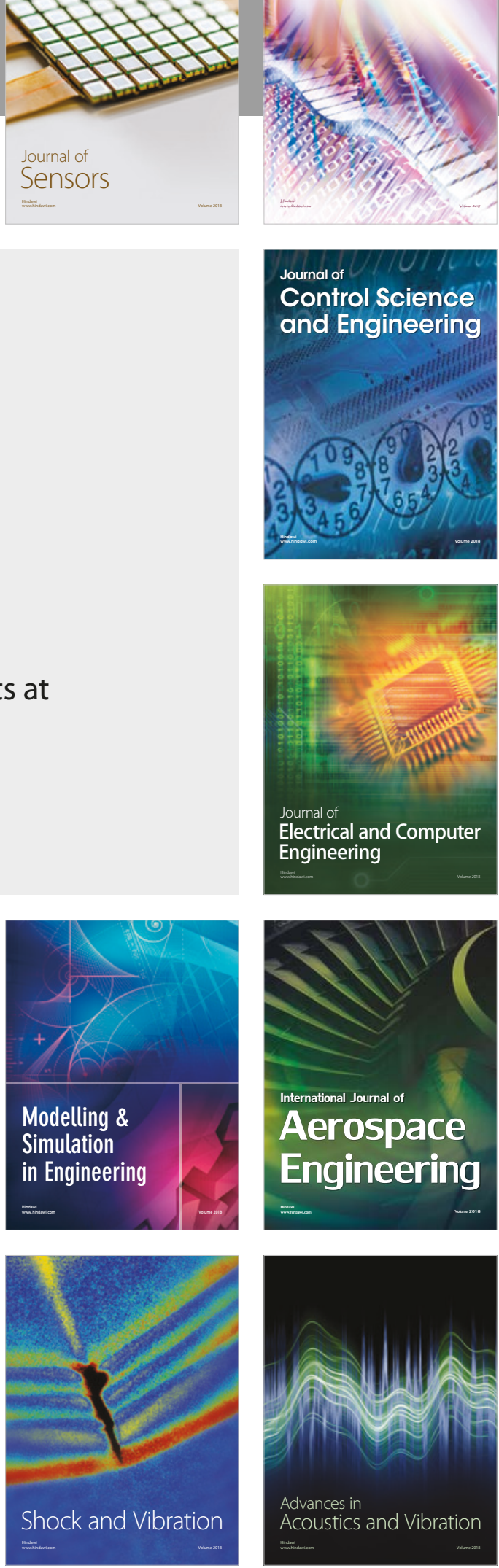